Florida International University FIU Digital Commons

\title{
Conservation Attitudes and Community Based Natural Resource Management in an Understocked Game Management Area of Zambia
}

Alexander Chidakel

Florida International University, achid001@fiu.edu

DOI: $10.25148 /$ etd.FI1 1080302

Follow this and additional works at: https://digitalcommons.fiu.edu/etd

\section{Recommended Citation}

Chidakel, Alexander, "Conservation Attitudes and Community Based Natural Resource Management in an Understocked Game Management Area of Zambia" (2011). FIU Electronic Theses and Dissertations. 450.

https://digitalcommons.fiu.edu/etd/450 


\section{FLORIDA INTERNATIONAL UNIVERSITY \\ Miami, Florida}

\section{CONSERVATION ATTITUDES AND COMMUNITY BASED NATURAL RESOURCE MANAGEMENT IN AN UNDERSTOCKED GAME MANAGEMENT AREA OF ZAMBIA}

A thesis submitted in partial fulfillment of the requirements for the degree of MASTER OF SCIENCE in ENVIRONMENTAL STUDIES

by

Alexander Chidakel 
To: Dean Kenneth G. Furton

College of Arts and Sciences

This thesis, written by Alexander Chidakel, and entitled Conservation Attitudes and Community Based Natural Resource Management in an Understocked Game Management Area of Zambia, having been approved in respect to style and intellectual content, is referred to you for judgment.

We have read this thesis and recommend that it be approved.

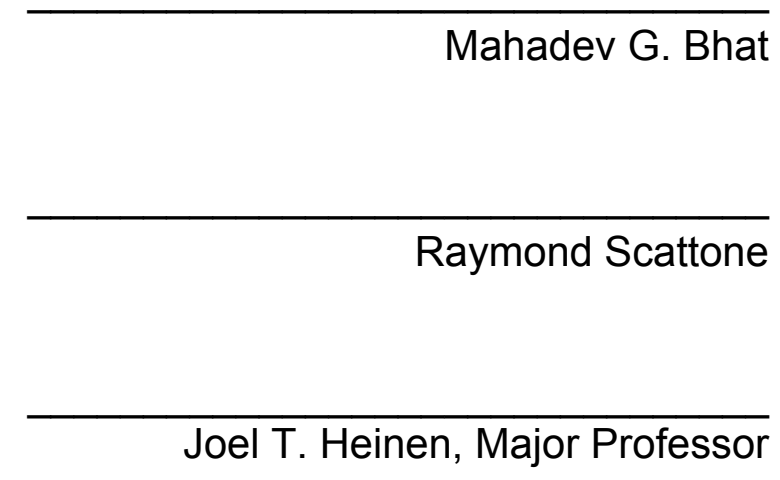

Date of Defense: June 24, 2011

The thesis of Alexander Chidakel is approved.

\begin{tabular}{r} 
Dean Kenneth G. Furton \\
College of Arts and Sciences \\
\hline Interim Dean Kevin O'Shea \\
University Graduate School
\end{tabular}

Florida International University, 2011 


\section{ACKNOWLEDGMENTS}

I thank the members of my committee and Dr. Joel T. Heinen for guidance and suggestions provided throughout the research and composition process. I am also thankful for the statistical consultancy and technical assistance with data manipulation offered by Andrea Roofe of the FIU office of statistical consulting.

In Zambia l'd like to thank Donald Phiri, associate Peace Corps director for the Linking Income Food and the Environment (LIFE) program for his generous and prompt accommodation of my research interests. Invaluable instruction in the Bemba language was provided by Whiteson Mwaba, also of Peace Corps. The staff of the Kasanka Trust, and especially Frederick Mbulwe, were of tremendous help, advising and supporting my work, and were often the only source of credible information. In the field I was aided by the translation and navigation services of Winter Muzuwa, Douglas Sibalwa, Gift Chiwila, Samson Chipulu, Morgan Mweenda, Albert Chisenga, William of Lusenga, Boneface Chingala, Godwin Mwengwe, and Benson Kalasa.

Graduate study at FIU was supported by a teaching assistantship from the Department of Environmental Studies and the research was made possible through the Masters International (MI) program of the US Peace Corps. 


\begin{abstract}
OF THE THESIS
CONSERVATION ATTITUDES AND COMMUNITY BASED NATURAL RESOURCE MANAGEMENT IN AN UNDERSTOCKED GAME MANAGEMENT
\end{abstract}

AREA OF ZAMBIA

by

Alexander Chidakel

Florida International University, 2011

Miami, Florida

Professor Joel T. Heinen, Major Professor

In an understocked game management area surrounding privately managed Kasanka national park in the Central Province of Zambia, local attitudes towards conservation and park-people relations were examined in the context of a community based natural resource management program. A semistructured questionnaire was administered to 260 households and a multiple linear regression was used to analyze the data.

Significant socioeconomic factors and attributes of households relevant in explaining positive conservation attitudes were education, employment with the park, and experience with outreach efforts. Outreach though is constrained by the limits on revenue generation of a small park, low communication of program purpose, and poor relations between park management and the chief. Support for conservation is undermined by antagonism between locals and wildlife scouts and crop damage by elephants. However, attitudes should improve with a 
strategy to address human-elephant conflict and enhance communication of the programs accomplishments and objectives. 


\section{TABLE OF CONTENTS}

CHAPTER

PAGE

1. INTRODUCTION 1

1.1 Background 1

1.2 Research Purpose: Understanding Conservation Attitudes 4

1.3 Context of Research: Conservation in Southern Africa 6

1.4 Study Area 25

2. METHODS 38

2.1 Selection of Study Site 38

2.2 Survey Instrument $\quad 39$

2.3 Sampling Method $\quad 40$

2.4 Qualification and Manipulation of Data 43

3. RESULTS 49

3.1 Demographic and Socioeconomic Characteristics of Respondents

49

3.2 Conflict Issues in Park Outreach and Management 59

3.2.1 Crop Damage by Wildlife $\quad 59$

3.2.2 Poaching $\quad 65$

3.3 Participation in Conservation 67

3.4 Conservation Attitudes $\quad 72$

3.4.1 Attitude Statements $\quad 72$

3.4.2 Overall Conservation Attitude $\quad 78$

4. DISCUSSION AND RECOMMENDATIONS 82

4.1 Impact of Outreach and Participation 82

4.2 Factors Undermining Support for Conservation and Some 90

Recommendations

4.3 Conclusion 93

$\begin{array}{ll}\text { LIST OF REFERENCES } & 96\end{array}$

$\begin{array}{ll}\text { APPENDIX } & 101\end{array}$ 


\section{LIST OF TABLES}

TABLE

PAGE

3.1 Education categories and percent of respondents in each category

3.2 Typical enrollment figures of local schools

51

3.3 Percent of households keeping livestock species and number kept

57

3.4 Percent of households selling resource types

58

3.5 Percent of households experiencing crop damage from wildlife in previous year

63

3.6 Percent of respondents formally participating in conservation and Outreach

3.7 Significance levels of predictors used in a regression model explaining conservation attitudes 


\section{LIST OF FIGURES}

FIGURE

PAGE

1.1 Africa and Zambia 26

1.2 Zambia and Kasanka NP 26

1.3 Kafinda GMA and Kasanka NP 31

3.1 Population pyramid of sampled households 49

3.2 Percentage of crop sales for all crops sold 54

3.3 Map of the 260 households surveyed 64

3.4 Percentage of positive response to each attitude statement

3.5 Mean attitude score and \% of respondents with positive attitudes for all VAGs, ordered by distance to park boundary 


\section{ABBREVIATIONS}

\begin{tabular}{|c|c|}
\hline ADMADE & $\begin{array}{l}\text { Administrative Management Design (for Game Management } \\
\text { Areas) }\end{array}$ \\
\hline BTL & Busanga Trails Limited \\
\hline CAMPFIRE & $\begin{array}{l}\text { Communal Areas Management Program For Indigenous } \\
\text { Resources }\end{array}$ \\
\hline $\mathrm{CBC}$ & Community Based Conservation \\
\hline CBNRM & Community Based Natural Resource Management \\
\hline CCRB & Chitambo Community Resource Board \\
\hline CRB & Community Resource Board \\
\hline GMA & Game Management Area \\
\hline ICDP & Integrated Conservation and Development Project \\
\hline KTL & Kasanka Trust Limited \\
\hline MoU & Memorandum of Understanding \\
\hline NGO & Non-Governmental Organization \\
\hline NP & National Park \\
\hline NPWS & National Parks and Wildlife Service \\
\hline PA & Protected Area \\
\hline VAG & Village Area Group \\
\hline ZAWA & Zambia Wildlife Authority \\
\hline
\end{tabular}




\section{CHAPTER 1: INTRODUCTION}

\subsection{Background}

The colonial expansion of the early $20^{\text {th }}$ century by European powers in southern Africa brought western value sets and centralized administrative systems to a complex landscape with a mosaic of ethnicities and numerous, distinct, and local norms, customs, and resource management regimes. To protect what was seen as a vulnerable resource, wildlife became the strict domain of government and subsistence use by local populations was largely prohibited (Child B., 2004). The exclusionary approach to conservation legally alienated an important resource to local populations without actually curtailing its use. By undermining the ability of local traditional institutions to manage wildlife the threat of overexploitation and unsustainable use continued to act upon a decreasing resource base. However, as the commercial value of wildlife grew in relation to alternative economic activities, through tourism development and safari hunting, and as the global conservation community began to appreciate the failures of protectionist approaches to conservation, the philosophical shift towards community-based conservation became manifest in southern Africa through new decentralized wildlife management programs (Adams and Hulme, 2001).

Starting with a communal areas management program in Zimbabwe, the first of its kind to devolve management authority and economic benefits to the local level, similar programs were either experimented with or became fully instituted in other countries in the region (Child B., 2004). Zambia in the late 
1980's developed its own program, administrative management design (ADMADE) for game management areas (GMAs) -inhabited areas adjacent to national parks - which allowed monetary benefits from safari hunting and sightseeing to accrue to communities and allowed communities to participate in wildlife management (ZAWA, 1998). In 1998 lessons learned from the ADMADE experience were incorporated into national legislation that provided for democratically elected community resource boards (CRBs), designating them the local institutions of management authority in each GMA. The CRBs are empowered to co-manage agreements with safari hunting and tourism operators, co-manage wildlife populations through quota setting, employ game guards, and develop land-use plans. More significantly CRBs are also entitled to a portion of the revenue collected from hunting and commercial concession fees as compensation for commercial wildlife utilization in GMAs (ZAWA, 1998).

A common objective of such community-based natural resource management (CBNRM) programs is to link biological conservation with economic development. By allowing local resource dependant populations to capture the economic benefits of resources, and empowering them to make decisions regarding resource use, incentives for conserving resources are expected to develop and guide behavior. However, by the turn of the century optimism about CBNRM had begun to wane as its record in Africa was highly variable (Murphree, 2009). It became clear that full and effective implementation of CBNRM required overcoming both resistance to devolution by governmental authorities and the limits to capacity and accountability within communities, and also required 
adequate revenue potential, an attribute frequently oversold (Wainwright and Wehrmeyer, 1998). Yet, for all the failures of CBNRM to deliver fully on its promise, it is seen as the only viable alternative to the "fortress conservation" model of the past (Murphree, 2009). A reversion to strict protectionism, with its more dismal record, has not been seriously considered, but where a community based approach to conservation is practiced near protected areas (PAs), such as national parks (NPs), elements of protectionism must necessarily be preserved and a balance struck between the two policies (Adams and Hulme, 2001).

The impact of CBNRM policies on conservation goals broadly, and on wildlife populations in particular, is confounded by concomitant efforts at antipoaching enforcement and is thus difficult to measure empirically. For example, money received by CRBs in Zambia is commonly used to hire scouts whose job it is to patrol for poachers, but it has been observed that with greater enforcement hunting methods have changed from using rifles to the more insidious practice of snaring (Marks, 2001). Incentive structures for communities are expected to change with implementation of CBNRM, but the same is also true for increased levels of enforcement. Conservation agencies and governments with limited funding provide much of the support for community development and outreach programs near protected areas but they also provide for enforcement, and though support for communities from these agencies tends to improve relations, enforcing the law can cast them in an adversarial light, resulting in mixed perspectives by community members (Anthony, 2007). An understanding of the proportional contribution to conservation by CBNRM and its 
role in changing behavior is therefore critical in planning effective protected area conservation programs that balance gains from a devolutionary approach with gains from conventional style enforcement. Such an understanding must begin with an evaluation of community members' attitudes on conservation against factors which might influence their perceptions.

\subsection{Research Purpose: Understanding Conservation Attitudes}

Perceptions or attitudes of members of a community living near a national park, as they relate to the use of resources, importance of conservation, the perceived value of the protected area, the management authority, and other subjects relevant to conservation may be compared with information obtained on demographic and socioeconomic attributes of the household. Correlations between the two sets of information can be identified and used to explain the most important factors in determining conservation attitudes (Heinen, 2010). The information can then be used to refine or adapt programs to better address shortcomings or oversights in policy and practice, and plan more effective programs in the future.

Attitudinal surveys have previously been administered in Zambia to determine the effectiveness of CBNRM projects. Results of one such survey (Wainwright and Wehrmeyer, 1998) showed that though the perceived importance of wildlife had improved, dissatisfaction and continued poaching meant the project was failing to meet its objectives and attributed the failure to, among other things, lack of awareness and understanding of the project. Among the recommendations the study made was for comparisons with other CBNRM 
projects, of different circumstance and location. As the government of Zambia has recognized the limits of its custodial capacity with respect to natural areas, and as it has increasingly sought partnership with private entities to assume managerial roles in protected areas of lesser commercial potential, the setting and practice of CBNRM around such privatized parks offers a unique opportunity to study the relationship between a non-governmental managing agent and a local population.

\section{Research Objectives}

The overall goal of this research is to evaluate the impact, by a CBNRM program that emphasizes protected area outreach, on the conservation attitudes of community members living outside a privately managed national park. Specific objectives include: 1) Assessment of overall conservation awareness and conservation attitudes, 2) Determination of knowledge and awareness of local conservation related institutions, 3) Identification of factors relevant in determining conservation attitudes and knowledge and awareness of institutions, and 4) Identification of social, economic, demographic, or policy issues that might prevent effective participation and cooperation, or support of the CBNRM program.

To guide the design of research methods the following hypotheses have been formulated.

- Conservation attitudes are significantly linked with at least some socioeconomic or demographic variables, including a positive link with education level. 
- Lack of knowledge or awareness and misunderstanding of CBNRM institutions and park outreach efforts, and related negative perceptions towards park agents have a negative influence on conservation attitudes.

\subsection{Context of Research: Conservation in Southern Africa}

Conservation narratives tend to be oversimplified and applied broadly across contexts and scales to interpret or predict outcomes. The fortress conservation model, so popular in colonial Africa, is widely considered illconceived and ineffective; the modern, development oriented model considered progressive and well suited to the underlying problems leading to habitat degradation and decline in wildlife and natural resources. However, on a finer scale and on account of differences in circumstances between countries and sites, a wide range of strategies in implementing community-based conservation $(\mathrm{CBC})$ has resulted in commensurate variability in success. But success itself is variably defined and relates to objectives. With the stakeholders multiplied near protected areas the objective of conservation, influenced externally, is less utilitarian and more bio-centric. Protected area management allows less compromise in the practice of $\mathrm{CBC}$ and is not exclusive of more conventional, punitive approaches to natural resource conservation. An opportunity is thus presented in a review of policies and programs, and parks and communal areas to identify the common impediments to effective community conservation, as well as the circumstances for which the rhetoric of the new narrative is maladapted, and which call for the retention of elements of protectionism. 


\section{Historical context}

The designation of protected areas and the first bans on hunting in Africa arose out of romantic notions of the wild and reverence for the sport of hunting among Europeans (Adams \& Hulme, 2001). As such, the first protected areas were game reserves in which members of the settler community could hunt. Corresponding protectionist legislation outlawing hunting among locals was of little practical consequence however. By the end of the $19^{\text {th }}$ century a combination of rinderpest outbreaks and the toll taken by colonial hunters run amok had severely reduced wildlife populations. Even when wildlife had recovered tsetse flies increased in tandem and, in defense of livestock, the eradication of wildlife outside of PAs was pursued at the same time that it was being protected within (Bond, l., et al., 2004).

A conservation ethic around wildlife among locals was not eroded by the imposition of game laws. No such ethic existed at the time. Harvesting of wildlife tended to be wasteful while it was abundant, though taboos existed for certain species. Traditional institutional mechanisms to regulate use were not needed, and as the evolution of these mechanisms arises out of the need to manage scarcity they did not exist. Rather, the real impact of anti-hunting legislation was to alienate local populations from the wildlife resource, negating their authority and pre-empting and precluding them from developing traditional institutions to regulate themselves by the time human populations grew and wildlife became scarce. The notion that wildlife belongs to the state, an artifact of British 
Common Law, remains deep seeded throughout southern Africa to this day (Bond, I., et al., 2004).

A second phase in the evolution of PA management in Africa occurred after World War 2 when an emerging western conservation ethic guided a growth spurt in the designation of parks in order to protect ecotypes from rapid agricultural expansion. Many such parks were upgrades of already existing game reserves. At the same time most of the modern day parks and wildlife departments were born. These new departments continued to follow a protectionist agenda, which was only reinforced by international media portraying Africa as a wild frontier, the last of its kind, and where large game populations were free and commonly found on unprotected land (Adams \& Hulme, 2001). The focus later broadened from game species to all threatened species of both fauna and flora and even aesthetics. However, not all aspects of management had been enlightened. The control of predators such as baboons and hyena continued through poisoning campaigns in order to enhance game populations under the false assumption that herbivores were limited more by predators rather than food availability (Cumming, 2004). Park management matured with the dawn of the science of conservation biology in the 1980s and new emphasis was placed on biodiversity, ecological functioning, and the linkage of large landscapes (Adams \& Hulme, 2001).

\section{Community Based Conservation}

Community-based conservation, and the idea that conservation and development can be linked is the latest phase in African conservation, born out of 
the $3^{\text {rd }}$ and $4^{\text {th }}$ World Congresses on National Parks in 1982 and 1992 (Adams \& Hulme, 2001). Despite the focus on safeguarding Africa's rich natural endowment, habitat continued to be lost at alarming rates and it was unrealistic to expect the perennial costs of strictly guarding species, both inside and outside of PAs, to be met in perpetuity. Community based conservation promised to reduce human pressures on nature and had the added bonus of working towards social justice in often neglected rural areas (Newmark \& Hough, 2000). Such an idea was not original. Economists at the time were advocating free markets as a counter to control by states, and the discourse of development had already shifted to bottom-up planning. By following suit, conservationists could capture some of the support and funding materializing out of the new enthusiasm for devolution (Adams \& Hulme, 2001). By 1996 there were already more than 50 integrated conservation development projects (ICDPs) in 20 African countries (Newmark \& Hough, 2000). The quick spread of CBC was facilitated by weak governments that relied heavily on foreign aid and that were easily influenced by aid agencies and their staff of expats and experts.

To fit a variety of countries and circumstances CBC has come to mean many things. To make useful comparisons between approaches to $\mathrm{CBC}$ the range of experiences may be abstracted into a set of typologies existing along the two dimensions of community control, and purpose. The degree of control a community has in the planning and implementation of an ICDP ranges in practice from consultative participation, in which communities are only consulted before decisions are made by outside agents, to full empowerment. Likewise, the 
purpose can be characterized as conservation for the sake of nature, or conservation for the sake of sustainable use of resources. Community based conservation programs around protected areas (discussed below) typically lies at the one extreme of these two dimensions (low community control, bio-centric purpose), while $\mathrm{CBC}$ at the other extreme (medium to high control, more development purposed) is represented by community based natural resource management (CBNRM), an approach with broader applicability across communal lands away from PAs (Adams \& Hulme, 2001).

\section{Community Based Natural Resource Management}

Community based natural resource management has its origins in southern Africa with Zimbabwe and Namibia being two centers of innovation (Jones \& Murphree, 2001). These are countries with a similar colonial history. During the colonial period white settlers appropriated land from blacks for farming, relegating blacks to communal land on which they lacked ownership of resources. After independence the situation for locals did not improve, as postcolonial governments tended to draw authority away from the customary leadership in such areas. Even on private land the state had appropriated wildlife in the interest of sport hunting, and, seen as grazing competition for livestock there was little incentive to conserve wildlife. In fact, settlers faced counter-incentives in the form of agricultural subsidies for beef and fertilizer that led to the culling of wildlife and fencing of land, thus curtailing migrations. As a result, by the 1980 s less than $10 \%$ of the herbivore biomass on the savannahs of 
Africa was composed of wildlife species. The remainder was livestock (Bond, et al., 2004).

The solution to the wildlife problem came out of recognition that one of the main reasons for its loss was competition with cattle. Legislation set to put wildlife and livestock on equal footing, favoring neither one nor the other by granting user rights to wildlife to private landowners. The economic environment by the ' 70 s and early ' 80 s had also turned auspicious. Agricultural subsidies were cut in accordance with structural adjustment programs and the imposition of a complete hunting ban in Kenya in 1976 sent clients south, allowing southern Africa to capture $70 \%$ of the market share in safari hunting. Farmers and ranchers began to shift their livelihoods from cattle rearing, which drew down the natural capital of soils, to the provision of hunting which had the advantage in being independent from ecological production (Bond, et al., 2004).

The great economic success of wildlife on private land had been proven, but remained in sharp contrast with communal land where locals were unable to profit from hunting. This legal inequity became more tenuous following a growing demand for the extension of proprietary rights over wildlife to communities, and after independence in the two countries the extension played out. Yet communities lack the legal and definitional clarity of titled land. How the countries of southern Africa have tackled this issue and attempted to translate the model from private land to communal land has followed several strategies, each with their own advantages and disadvantages. 
Namibia, in the 1990s, bypassed the necessarily arbitrary debate of what constitutes a community by allowing communities to define themselves. Through a process of internal negotiation, once communities drew their own boundaries and drafted a constitution they could qualify for the designation of "conservancy". Communal conservancies would then be granted the same rights to wildlife enjoyed by private landowners (Jones \& Murphree, 2001).

The drafters of Zimbabwe's communal areas management program for indigenous resources (CAMPFIRE) did not go as far as their counterparts in Namibia. Rather than allowing communities to define and empower themselves by seizing a right that had been granted through legislation, proprietorship in Zimbabwe landed at a district level institution of government, the rural district council. This policy represented power decentralization, if not devolution, and was a compromise of the principals of CBNRM which emphasize benefit and empowerment. Communities experienced some devolution of management and retained $50 \%$ of revenues but rights remained with the councils. There were certainly documented successes of the CAMPFIRE program, but quick bureaucratic acceptance came at the cost of aborted devolution and the separation of responsibility from authority; a politically enabling condition, but one that limits long term prospects (Jones \& Murphree, 2001).

A third approach to devolution, as seen in Zambia, was less a response to a economic distortions than an attempted solution to a wildlife crisis and came after a wave of poaching for high value rhino horn and elephant ivory had hit the country. The collapse of the copper market in 1975 rippled through the Zambian 
countryside where the government was forced to reduce the price it offered small scale farmers for maize. Rural incomes declined and as demand from increasingly wealthy OPEC countries grew for wildlife products poaching became an attractive alternative to rural populations near PAs (Gibson, 1999).

The National Parks and Wildlife Act of 1968 had already re-designated former controlled hunting areas as GMAs, but control over wildlife remained centralized with the State (Manning, 2010). However, in the 1980s the Department of National Parks and Wildlife Service (NPWS) began experimenting with granting co-management opportunities and sharing revenue from safari hunting with communities outside NPs. The strength of traditional leaders rendered the question of "devolution to whom?" less problematic. The units of proprietorship over wildlife were designated at the level of the chiefdom, that is, the GMA, where authority would rest largely with chiefs (Jones \& Murphree, 2004). It was only in 1998 that devolution was made a formal legislative right under the Zambian Wildlife Act (ZAWA, 1998). Again, design and implementation was a product of compromise, resulting in numerous obstructions to the achievement of ideals, but for all the problems that have plagued CBNRM in these and other countries (discussed below) it has contributed to conservation in ways both tangible and abstract. Land outside of protected areas is no longer being neglected. Five million hectares of habitat in Namibia alone have been given due regard and secured in conservancies. Perceptions of wildlife have also improved. Wildlife is now seen by many as an asset to be managed, rather than a threat to agriculture, and claims of reduction in poaching are promising, 
though they tend to be anecdotal. That is to say nothing of developmental achievements, including the promotion of rural democracy through the fostering of local level institutions for the management of resources that may also serve in negotiations with government and other actors (Jones \& Murphree, 2004).

\section{Problems with Community Based Natural Resource Management}

A reform of power and revenue structures as ambitious as that undertaken through CBNRM must overcome significant and competing vested interests that threaten to undermine the foundations of benefit and empowerment. Such a reform is a practical challenge of negotiation and implementation. Yet the very theoretical basis of $\mathrm{CBC}$, in all its forms, has also come under question.

Benefits experienced as a result of revenue distribution in ICDPs are commonly in social infrastructure improvements such as schools, roads, and clinics. As public goods these benefits allow free-riding. Whether one adopts conservation minded attitudes and behaviors is independent of the ability to enjoy the social and economic development that such projects bring. The consideration of free-riding is especially important because the social value of activities communities are expected to refrain from is often ignored, and thus incentives for non-compliance underestimated. When, for example, all hunting quotas were allocated to commercial use in the Luangwa valley of Zambia, and none left for subsistence purposes, those whose skill was in hunting were left with no alternative but to poach (Wainwright \& Wehrmeyer, 1998). In this case collective benefit may have been maximized, but only when put in terms of strict economic value. 
Even when economic benefit is significant, what matters ultimately is net benefit. For communities to become partners in conservation this frequently entails enduring the opportunity cost of foregoing agriculture on sensitive land, and the costs of living with wildlife, including crop damage and livestock depredation. Combined, these costs may outweigh the benefits (Bandyopadhyah \& Tembo, 2010).

A number of assumptions serve as premises for $\mathrm{CBC}$ yet some are not universally true, while others have not been adequately tested. For one, the adoption of a conservation ethic does not necessarily follow from the experience of benefits. The Nama people living near Richtersveld NP in South Africa saw a revenue distribution scheme as a mechanism for development, but only one such mechanism, competing amongst other, potentially more lucrative and environmentally harmful activities such as mining. Additionally, exposure of locals, through park employment, to the sometimes idiosyncratic values of westerners towards nature, and, from a local perspective, the obscure and useless species they are seen to pursue, may have undermined the perceived legitimacy of the concern for nature espoused by outsiders (Boonzaier, 1996). Provision of employment elsewhere, as in Zambia, has improved living standards, but in Madagascar former poachers hired by a park used their income to continue to fund poaching activities by proxy (Newmark \& Hough, 2000).

Another assumption rarely acknowledged is that behavioral modification necessarily follows the adoption of a conservation ethic. Enlightened views on resource management and the value of nature do not dismiss the dictates of 
necessity in rural areas where, for want of alternatives, a newfound morality is easily sacrificed to the attainment of a certain quality of life. It is an inherently difficult assumption to test, as observation of both attitudes and behavior must be documented for each individual surveyed, with all the potential for bias that behavioral observation introduces. However, a study from Tanzania suggests that, at least for the collection of firewood, those having more positive conservation attitudes were more likely to use sustainable methods of wood extraction. It is though a rare question to be asked (Holmes, 2003).

Of relation to benefits, the revenue potential, as a ratio of the value of an area's resources to its human population, is critical for success but is frequently oversold (Balint, 2006). In Zambia, poor infrastructure limits the season for tourism to many NPs, and as a consequence, even with resource recovery, increased tourism is not guaranteed (Bandyopadhyay \& Tembo, 2010). The low quality of roads is especially pertinent for smaller, remote PAs, located off the main tourist pipeline to the more celebrated of Zambia's parks. Outside of Zambia, there are few parks in Africa where gate fees cover the direct costs of conservation, let alone what is needed for communities to benefit.

Compounding the problem of revenue shortage, complete devolution of hunting or tourism revenues to communities is not common. As mentioned, district councils in Zimbabwe keep 50\% of revenue from wildlife, as does the Zambian Wildlife Authority (ZAWA; Musumali, et al., 2007). Zambia has also been criticized for allowing only passive participation by communities (Bandyopadhyay \& Tembo, 2010). That is, participation is seen by the Authority 
as serving to meet its own predetermined objectives. The limited capacity of a CRB in the Luangwa valley, as well as a general lack of community involvement in resource boards throughout Zambia has been attributed to the opacity of ZAWA, its retention of both revenue and final authority on hunting quotas, and its restriction on resource use to only certain non-timber forest products (Musumali, et al., 2007).

Indeed, the inertia of centralized governmental institutions does make it difficult to shift control to lower levels, but a lack of devolution is also sometimes a result of an initial lack of capacity at these levels. Poorly functioning CRBs tend also to lack transparency and do not perform well at informing the general community of their remit and the process of CBNRM. Almost $40 \%$ of a community outside South Luangwa NP knew nothing at all of such a program, and many others thought the objective was in conservation, not development (Musumali, et al., 2007). By promoting democratic empowerment, capacity should be expected to improve over time. But if enthusiasm gets the better of pragmatism and projects are launched into too soon the possibility of elite predation is opened up, a problem in its own right.

In an early version of Zambia's CBNRM program chiefs were given a large degree of control, allowing them to allocate individual employment opportunities, acquire assets such as grinding mills, and generally capture or use to their advantage most of the benefits. That customary leadership had appeared at first the appropriate repository of communal rights highlights, again, the difficulty of the task of designating proprietorship over communal resources. The attribute of 
Zambian chiefs that went overlooked or underappreciated was their subjugation under the colonial authority, a fact that eroded the traditional checks on their power and made them more accountable upwards to government, and not downwards to their subjects (Virtanen, 2003).

Given such adversities, all threatening to undermine the objectives of devolution, $\mathrm{CBC}$ must be considered a process, and one that, given time and support, may adapt to challenges both intrinsic and external. It must not be considered a static state of affairs and relations, however so much they conform to design, off which judgments of success or failure are final. But this qualification is not entirely compatible with common development perspectives that are short term in nature. Funding timelines of 3-5 years are typical, followed by one-off assessments (Adams \& Hulme, 2001). Rarely can a project demonstrate self-sufficiency in so few years and in such cases more funding may be prescribed. But a tendency to treat problems with money can create ultimately self-defeating dependencies with communities. Ideally support should be long term, and funding directed more at capacity building than benefits.

\section{Community Based Conservation as Protected Area Management}

Where natural resources, including wildlife, are concentrated in or are near to official PAs the legislated mandate to protect biodiversity limits the degree to which compromise can be achieved between resource managers and communities dependant on natural resources. If extraction or the harvesting of resources from a park is strictly prohibited, and if a park, free from threat of land conversion, is a permanent source of human-wildlife conflict, the costs and 
problems imposed by a PA on local people may not only be more significant, but also less given to remediation when devolution of control is not possible. The formal establishment of parks also frequently results in the displacement of communities and the imposition of regulations in newly designated buffer areas. In such circumstances the emphasis of $\mathrm{CBC}$ is instead placed on devolution of benefits, conservation sensitization, and conflict resolution (Kaltenborn, Nyahongo, Kidegesho \& Haaland, 2008). The sharing of revenue, promotion of development, and provision of jobs, insofar as it compensates costs associated with living near a park, becomes the primary mechanism through which conflicts are resolved (Barrow, et al., 2004).

It is in the risk prone buffer zones of parks where conflict is highest and where the most vulnerable people are often forced to settle, relegated to less desirable land by traditional leaders respectful of socioeconomic status. For example, immigrants near Kibale NP in Uganda were disproportionately represented around the park's edge where they experienced higher rates of crop loss to wildlife (Naughton-Treves, 1997). The relatively poor may not only be more exposed to risk, but their capacity to cope with threats to their livelihoods is also constrained by their limited means. However, recent evidence from growth rates of human populations residing in $10 \mathrm{~km}$ buffer areas around parks in Africa and Latin America suggests that these negative factors are being counterbalanced by the positive economic and ecological externalities of parks, the employment opportunities parks offer, and the local socioeconomic development brought by ICDPs and funded by foreign aid (Wittemyer et al., 
2008). If such benefits are acting to draw immigrants from other, poorer, and sometimes culturally distinct areas, there is a potential for new problems resulting from the destabilization of social order. The challenge then faced by park authorities is, paradoxically, to continue to promote the local benefits of PAs while at the same time preventing the increased pressure and friction brought on by growing and diversifying human populations attracted to such benefits.

The responsibility locals ascribe to park authorities for conflicts related to wildlife adds another dimension to CBC near protected areas. For example, crop damage from wildlife is common anywhere wildlife and humans co-exist, but near PAs there is often an expectation of compensation from the government (or worse, a sentiment that animals of a park are sent out by park managers to harass villagers) (Boonzaeir, 2006). Conflict and antagonism can also characterize the relationship between law enforcement and the community members whom they occasionally suspect of and arrest, beat, or kill for poaching (Wainwright \& Wehrmeyer, 1998). A critical difference though, between CBC as PA management and $\mathrm{CBC}$ centered on communal lands is in the power relations between local populations and government, the ultimate authority over PAs.

Near PAs bargaining power held by communities is low, and communities tend to be defined more by the project, as opposed to being natural entities, and have limited ability to devise management plans (Balint, 2006).

External involvement by non-governmental organizations (NGOs) is also common. In Uganda, where potential for tourism revenue is low, benefit programs have been implemented that distribute money from donors and NGOs 
instead. But with outreach handled by NGOs and PA management performed by a government agency activities may not be coordinated. The result is that management may continue according to a protectionist agenda, albeit a refined one. Communities have even come to associate development activities with the facilitating NGO, and not the park itself. Despite power asymmetries, the political pressure communities may be able to bring to bear on park authorities can be considerable. In Uganda, for example, conflict around Bwindi Impenetrable Forest NP resulted in legislation allowing for up to $20 \%$ of a NP to be used for sustainable extraction of resources (Hulme \& Infield, 2001).

Conflicts between communities or NGOs managing outreach, and government agencies managing PAs are interesting because they represent a reversal of a value continuum seen between different scales of society. At the international level bio-centric values hold more sway, whereas at the national and local level of developing countries wildlife is seen more for its economic and utilitarian value. Governments, somewhat suspicious of a supra-nationally coordinated conservation agenda in undermining state sovereignty and upsetting national developmental priorities have, it has been said, used conservation policies as a way of expanding state power at the rural level (Virtanen, 2003). This may explain why agencies are reluctant and opposed to giving participatory rights to communities, even though, paradoxically, it is the extension of these rights that promises most to maximize economic and use values.

All is not conflict however, and the relationship between PA managing authorities and communities has been observed to improve with employment 
opportunities provided by parks, as well as with increased visitation and communication with communities by park representatives (Holmes, 2003).

\section{Privatization of Conservation in Africa}

If the push towards a conciliatory, community oriented conservation program around PAs came from the outside donor community, the flexibility in being able to effectively implement the approach, and adapt to a new philosophy was made possible largely by the privatization of wildlife and parks departments.

Political accountability suffers under centralized power structures with opportunities rife for the exploitation of wildlife for purposes of political patronage. Zambia's former NPWS was particularly corrupt, known for nepotism in hiring practices, and an inability to stop poaching when the ruling party campaigned on returning wildlife to the people (Gibson, 1999). But governments have recognized this, as well as the economic potential of wildlife - fully demonstrated outside the state sector - and a recent trend is for agencies to become parastatals with enhanced commercialization and links to the private sector. Parastatals, because they are divorced from government budgets have an advantage in the performance attributes of cost efficiency, and revenue generation, and have a political advantage in being insulated from government interference. Currently over half of the park authorities in southern Africa have been privatized (Child, 2004).

In Zambia, privatization resulted in the transformation of the NPWS into ZAWA over a 4 year period starting in 1998. The NPWS had been cited for its failure to reach its goals in $\mathrm{CBC}$ and PA management. It was also considered 
too centralized and subject to political interference. The Zambian government hoped to account for these deficiencies with the creation of ZAWA, an autonomous body, supported by the 1998 Zambia Wildlife Act, and governed by a board of directors (ZAWA, 2006). Though initial excitement about the transition turned into frustration when donors were turned off by quick, deep cuts made to staffing levels, ZAWA now enjoys steady donor support and has made improvements to the equity and transparency of the process by which concessions are awarded (Child, 2004).

One important implication of privatization, with a more financial and modular focus on cost centers, is the degree to which this changes an agency's broad scale political mandate to support conservation at all parks, even the less profitable ones (Child, 2004). Subsidization of less viable parks reduces incentives where conservation is more successful. On the other hand, to concentrate resources on successful parks is to sacrifice the quality of others. A potential solution to this problem can be found in Zambia, where major parks fund themselves and some lesser parks have been outsourced to NGOs. Currently four public-private partnerships for the management of protected areas exist in Zambia, with a fifth in development (Pope, 2006).

Kasanka NP was the first such partnership PA. At under $450 \mathrm{~km}^{2}$, Kasanka NP is relatively small for a national park, and due to a history of poaching is considered understocked (ZAWA, 2007). Originally a game reserve that was established in 1946 requiring the resettlement of a local community, it was granted NP status in 1971. Through neglect and incapacity though, there 
was little done to safeguard the park's wildlife and by 1985 it had become severely depleted of game. The arrival of that year of David Lloyd, a former district officer, who visited the park on a fishing trip was the first in a series of events that put the park's management on a new and experimental course. Hearing the sound of gunshots, Lloyd concluded that the park was not yet totally devoid of game and there remained something to save. Teaming up with Gareth Williams, a local commercial farmer, they set about using their own resources to improve and extend the park's infrastructure and hire wildlife scouts to patrol for poachers. In order to build on these initial efforts the Kasanka Trust (KTL), a limited liability non-profit organization, was formed two years later in Zambia, and registered as well in the UK (Farmer, 1992). The trust was successful in attracting additional outside funds from the donor community. With tourism to Kasanka increasing the NPWS recognized the progress made, and in view of their lack of resources agreed in 1990 to enter into a memorandum of understanding $(\mathrm{MoU})$ that allowed $\mathrm{KTL}$ to manage the park and develop tourism (ZAWA, 2002). Since the transition of the former NPWS into ZAWA in 2003 this MoU has been renewed twice, at 5 year intervals. With the ability to hire its own armed law enforcement contingent, retain revenue, and perform all management duties KTL has been largely successful in its rehabilitation efforts. As a nonprofit NGO, KTL has been forced to develop the park cost-effectively, for example with the work of semi-volunteers in the construction of infrastructure and accommodation (KTL, 2010). Yet the small size of the park and the slow rate of recovery of wildlife populations mean that tourism and tourism revenue will likely 
remain low. Donor support currently covers more than half the costs of management. The approach taken by KTL is therefore an inexpensive model appropriate for lesser parks in need of protection and restoration, but the question becomes how much interest there is in park rehabilitation for the model to be more widely applicable.

Implications of privatization for community welfare and relations are generally thought to be positive (Child 2004). Non-governmental organizations such as KTL have proven very willing to engage communities and win their support, for example through benefit sharing programs. Their ability to do so is not surprising given their smaller remit, local focus, and greater accountability compared with state agencies. However, public-private partnerships in conservation in Zambia have also been criticized for having greater ties to the government than to the communities in which they operate, and for failing to fully decentralize control of resources (Manning, 2010).

\subsection{Study Area}

\section{Zambia}

Zambia is a landlocked country located in south-central Africa (Figs. 1.1 and 1.2) with a population of approximately 14 million people and a total area of over $750,000 \mathrm{sq} \mathrm{km} \mathrm{-} \mathrm{roughly} \mathrm{the} \mathrm{size} \mathrm{of} \mathrm{the} \mathrm{state} \mathrm{of} \mathrm{Texas.} \mathrm{It} \mathrm{is} \mathrm{ethnically}$ diverse with 73 different tribes, 7 major native lingual-cultural groups, and significant minority white and Indian populations. A former British colony, it gained independence in 1964, but remains one of the poorest countries in the world (CIA, 2011). 


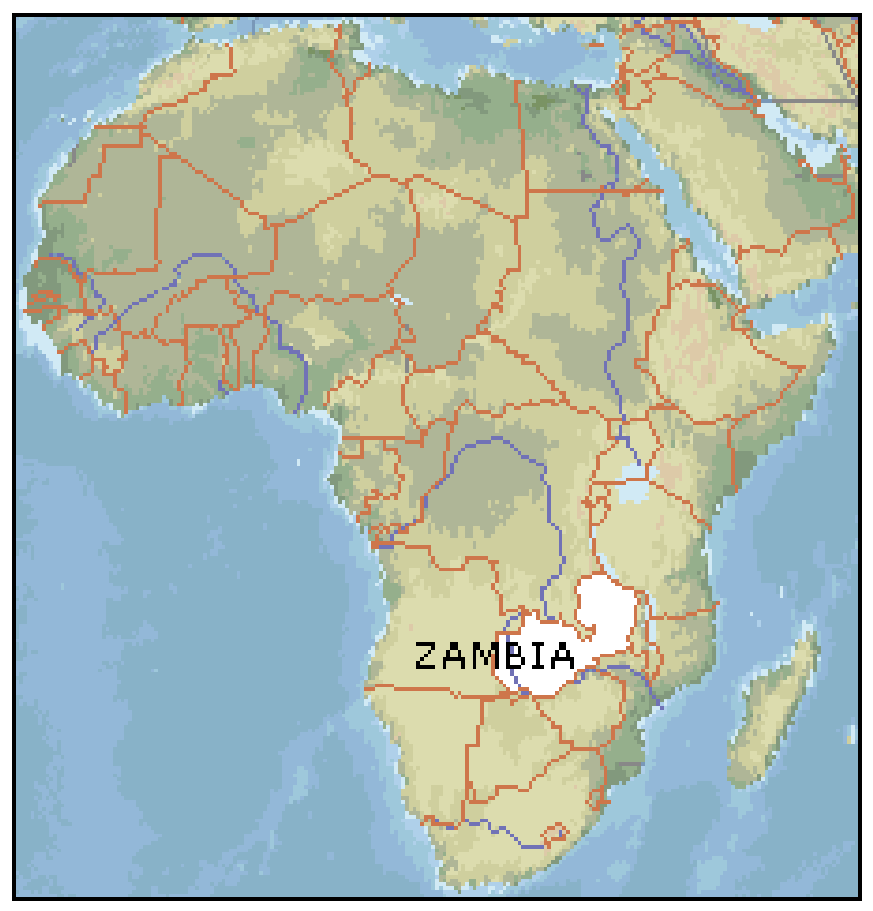

Figure 1.1: Africa and Zambia

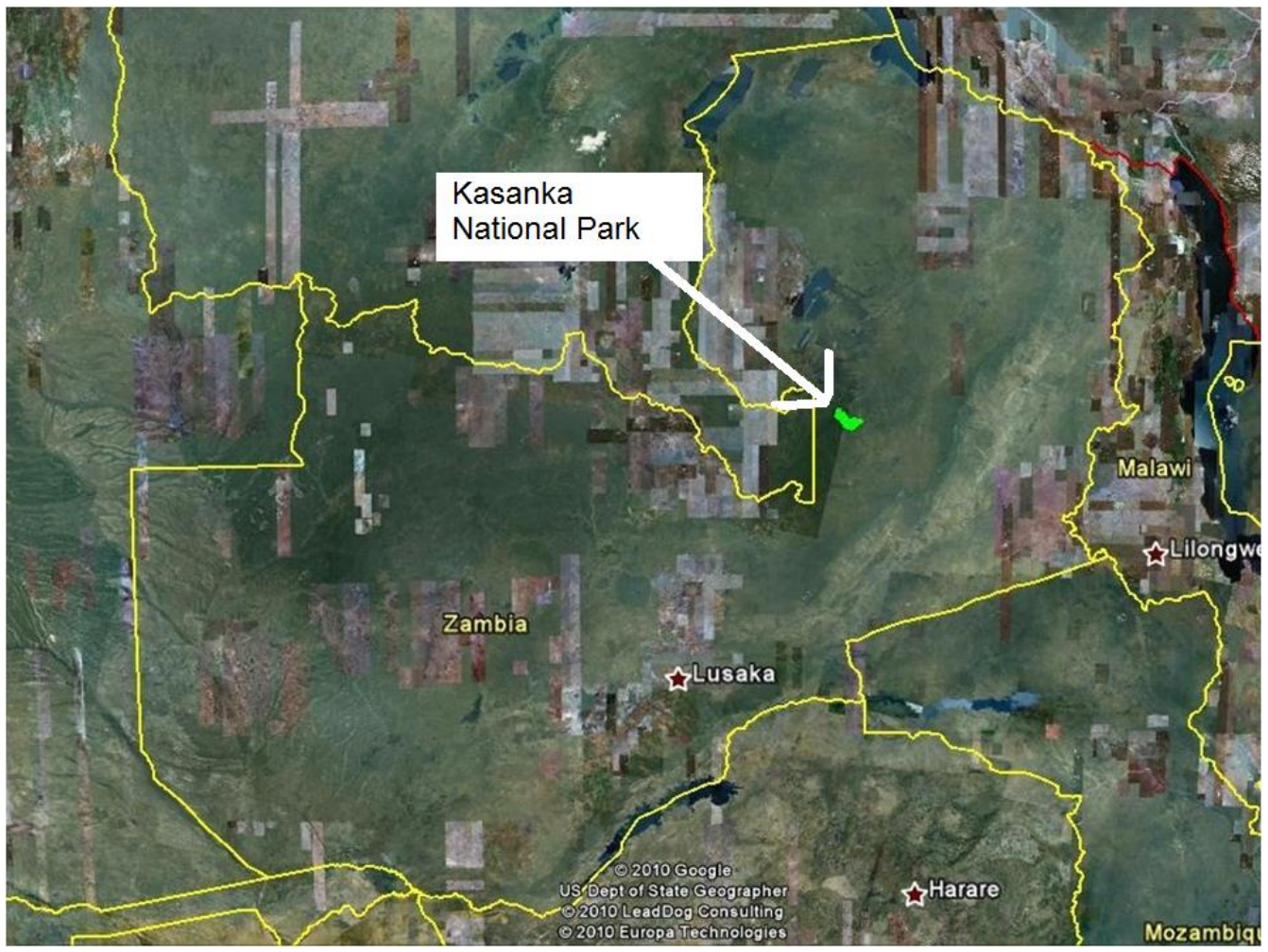

Figure 1.2: Zambia and Kasanka NP 
The published accounts of David Livingstone and other missionaries in Zambia in the mid-1800s fed the interests and ambitions of a great many British explorers and adventurers. By the 1880s the scramble to stake claim to the economic resources on the continent was well underway. Prominent among the men looking to control and profit from mineral rights in Southern Africa was Cecil Rhodes, the owner of the British South Africa Company. By sanction and authority of the British government Rhodes made treaties with chiefs across Zambia - Northern Rhodesia at the time - in exchange for the rights to minerals in their territory (DOS, 2011).

Until 1924 when the British Colonial Office assumed control the country was administered as a territory of the British South Africa Company. During this time little except labor was exploited from the country for the supply of mining operations in Rhodesia (modern day Zimbabwe) and South Africa. However in 1928 large copper deposits were discovered in what is presently the Copperbelt province, drastically transforming the national economy and society. Northern Rhodesia became a major world supplier of copper, and mine labor was drawn from all parts of the country, disrupting and destabilizing rural villages (Grotpeter et al., 1998).

In 1964, after the growth of a black bourgeois discontent with the inequity of power relations which were based on race, a civil disobedience campaign forced the British Colonial Office to allow elections for an independent government. The new country was renamed Zambia (Grotpeter et al., 1998). 
In the nationalistic period following independence economic emphasis continued to be placed on developing Zambia's mineral resources, although the production of maize was also encouraged to ensure the country's food security. However, the collapse of the copper market in the 1970's devastated the national economy (DOS, 2011). Unable to pay interest on international debt, the International Monetary Fund became increasingly involved in fiscal affairs. Structural adjustment programs had especially severe consequences on rural populations, as discussed above, when subsidies for food and agricultural inputs were withdrawn (Gibson, 1999). The economy has yet to recover its preindependence mark, and this is illustrated by per capita income, which at $\$ 1,500$ not only ranks $202^{\text {nd }}$ in the world but is less than the per capita income during the colonial period. Two thirds of Zambians live in poverty (CIA, 2011).

Social indicators reflect a similarly dire situtation. Life expectancy stands at 39 years and maternal mortality at 101 per 1,000 live births. The population growth rate of $3.062 \%$ is the $11^{\text {th }}$ highest in the world. Greater than a third of the population resides in a few urban areas; rural areas are underpopulated. The HIVIAIDS pandemic compounds the challenge of reversing the trend of poverty, while reducing the infection rate of $14.3 \%$ is considered itself one of the greatest challenges the country faces (DOS, 2011).

\section{Land Tenure and Administration}

Approximately $94 \%$ of Zambia's land mass is designated as customary land, the remainder being state and leasehold land. Customary land is characterized by communal, rather than individual ownership. It is the duty of the 
nation's 240 chiefs to manage and allocate land among their capable subjects who may utilize the land for agriculture and the collection of forest products. In practice, the duty is usually delegated to the chief's headmen. No single person, regardless of their occupation of allocated land, holds exclusive tenure rights or the right to sell, but land may be passed down or transferred along family lines. Ultimate discretion resides with the traditional ruler who may appropriate and reallocate occupied land without cause (Mudenda, 2006).

The 19 NPs may overlap with state and customary land boundaries and together make up $8 \%$ of the nation's land area. The 35 GMA's surrounding NPs cover $22 \%$ of the nation's land area (Mudenda, 2006). Within GMAs land and resource management is a shared function of the CRB and the chief, who is patron of the board. The specific functions of a CRB are outlined in Part III of the Zambia Wildlife Act of 1998 and are reproduced here:

"(1) The functions of a board shall be to promote and develop an integrated approach to the management of human and natural resources in a Game Management Area or an open area falling within its jurisdiction.

(2) Without prejudice to the generality of subsection (1), a board shall have power to:

(a) negotiate, in conjunction with the Authority, co-management agreements with hunting outfitters and photographic tour operators;

(b) manage the wildlife under its jurisdiction, within quotas specified by the Authority;

(c) appoint village scouts to exercise and perform the duties of a wildlife police officer under the supervision of a wildlife police officer in the area falling under the board's jurisdiction; 
(d) in consultation with the Authority, develop and implement management plans which reconcile the various uses of land in areas falling under the board's jurisdiction;

(e) perform such other functions as the Authority or Director-General may direct or delegate to it."

(ZAWA, 1998: p. 17)

The CRB is a second generation co-management institution born out of the 1998 act and derived from the Wildlife Management Sub-Authority of the ADMADE era. Because one of the major flaws of ADMADE was the degree to which power was concentrated in chiefs, including the ability to appoint members to the Sub-Authority, CRBs are formed through democratic elections. Decision making processes in the management of resources are further democratized and decentralized by the two-tier structure of CRBs. Democratically elected Village Area Groups (VAGs) are delegated by the CRB with the task of conducting needs assessment, project implementation, and resource and financial management at the village level, whereas the CRB itself provides leadership and coordinates the activities of all VAGs in a GMA (ZAWA, 2006).

\section{Kafinda GMA}

Located in the northern part of Serenje district in Central Province, Kafinda chiefdom, alternately referred to as Chitambo chiefdom, subsumes Kasanka NP (Figs. 1.2 and 1.3) and is a designated GMA under the traditional leadership of Chief Chitambo IV. The chiefdom covers more than $4,000 \mathrm{sq} \mathrm{km}$ and is settled by approximately 35,000 members of the Bemba-speaking Lala tribe with only minor representation from other Zambian tribes (KTL, 2010). 


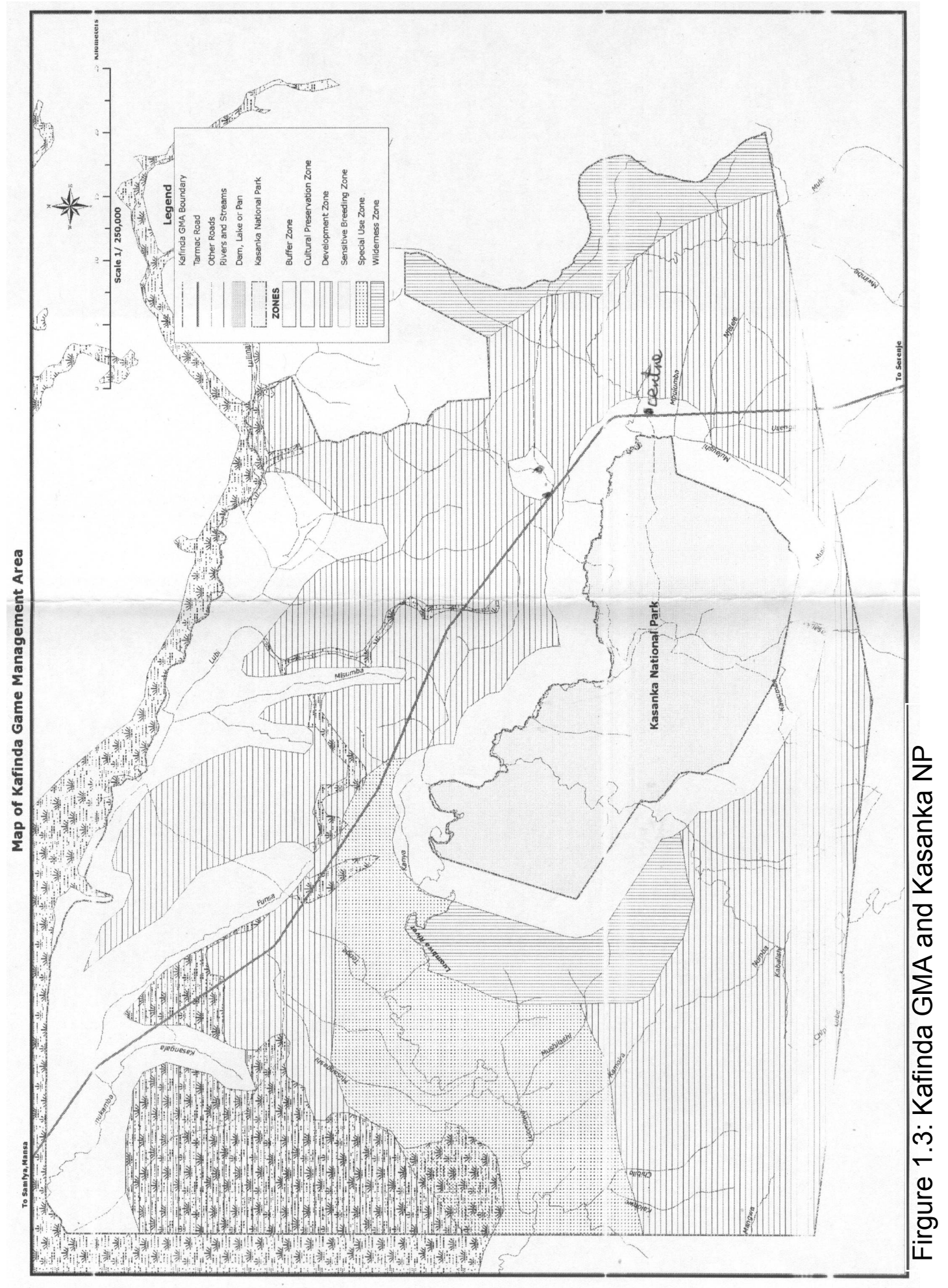




\section{Agro-ecological Description}

Kafinda GMA is situated at the southern extent of agro-ecological zone III in Zambia. Zone III is characterized by high rainfall, receiving more than $1000 \mathrm{~mm}$ per year, and a growing season of 180 days that lasts roughly from midNovember to mid-May. The dominant soil type throughout Serenje district is the acrisols, though the soil is also very sandy, especially in the northern part of the district nearer to Lake Bangweulu. Owing to the high rainfall, these soils are highly leached, of low fertility and have limited production potential in the absence of artificial fertilizers (UNZA, 2004). The topography is mostly flat, at an average altitude of $1200 \mathrm{~m}$ above sea level and the GMA is drained by two rivers, the Luombwa in the west, and the Lulimala which defines the boundary of the GMA to the north. These rivers form part of the Congo River basin.

The vegetative cover of the GMA mostly resembles the country at large. The dominant plant community is the miombo woodland, a two-storied open canopy forest consisting of evergreen and semi-deciduous trees growing to heights of $15-20 \mathrm{~m}$. The most common tree species in the miombo are of the genera Brachystegia and Julbernardia (UNZA, 2004). The forest is also interspersed by numerous shallow, seasonal wetlands.

\section{Infrastructure}

A single paved road connecting the Great North Road to the city of Mansa in Luapula Province bisects the GMA, though traffic is minimal at all times with intervals between passing vehicles about $30-60 \mathrm{~min}$ during the middle of the day. There is no electrical grid, and becoming increasingly uncommon in Zambia, 
there is no network access for cellular telephones either. Government presence is limited to basic and middle schools, rural health clinics, a local courthouse, and a ZAWA office.

\section{Agriculture and Livelihoods}

Subsistence farming, principally of maize and cassava, is virtually the only livelihood practiced in the GMA, and is supplemented by extraction of forest resources for food and construction. Consistent with other rural areas of Zambia education levels are extremely low, and most live in extreme poverty with food shortage a perennial concern. To cope with poor soils in the absence of fertilizer a variation of a traditional form of shifting cultivation called the chitemene system is used. Trees are chopped down in a field and the wood is collected into large piles where it is then burned after a drying period. The ashes are scattered over the soil to lower the acidity and introduce phosphorous, thereby increasing soil fertility.

Trees are also cut down in the harvesting of fuelwood for cooking, though fire also serves a social purpose as a centerpiece, drawing families together for several hours at night, particularly during the cold season. Both charcoal and raw wood may be used. In the case of raw fuelwood harvesting, trees are usually coppiced at above a height of $30 \mathrm{~cm}$ to allow regrowth, but the combined scale of fuelwood extraction, charcoal production, and the practice of chitemene is a serious threat to forests and soil stability in the game management area (KTL, 2010). 
Poaching for bushmeat (discussed further in results) is another livelihood strategy around Kasanka, though the illegal nature and discreteness of the activity prevents an estimate of the number of people involved. Nevertheless it is recognized as a major problem exerting great pressure on the wildlife populations of the park (KTL, 2010). The number of dambos and the proximity of the Luapula River to the north also promote fishing. Fish may be used to supplement household protein consumption, or sold in local markets or to buyers in urban areas. The use of harmful and unsustainable fishing methods, though, has reduced fish populations and the size of individual fish (F. Simba, pers. comm., 2008). These methods include the indiscriminate poisoning of water bodies using a natural poison (Ubuuba) extracted from the leaves of a tree (Tephrosia vogelli), the use of mosquito bed nets in weir construction, and the continuance of fishing during a 3 month ban covering the spawning season. The latter two practices are illegal but carried out with impunity.

\section{Kasanka National Park}

The unique management arrangement and history of Kasanka NP have already been discussed. The park itself covers nearly $430 \mathrm{sq} \mathrm{km}$ of mostly miombo woodland, with small clumps of thick evergreen forest, lake basin "Chipya" woodland, dambos, rivers and streams. Puku (Kobus vardonii) are the most abundant large mammal species but the shy sitatunga (Tragelaphus spekeii) inhabiting the marshes and papyrus swamps are perhaps nowhere in Africa better observed. Less common antelope species include roan (Hippotragus equinus), sable (Hippotragus niger), and hartebeest (Alcelaphus 
buselaphus). Yellow baboons (Papio cynocephalus) and vervet monkeys (Chlorocebus sp.) are two frequently sighted primates. The park is most well known for an annual migration of up to 10 million straw-colored fruit bats (Eidolon helvum) which come to roost in a patch of "mushitu" forest from October through December. It is one of the largest migrations of fruit bats in the world. Leopards (Panthera pardus) are the only resident large carnivores but are rarely seen. Crocodiles (Crocodylus niloticus) are found in Kasanka's rivers but rarely venture outside the park. Fears over man-eating tendencies of the district's lion population led to an eradication campaign in the 1960's and today the occurrence of lions (Panthera leo) is rare and only transient individuals have been observed. Two of the more dangerous animals are the elephant (Loxodonta Africana) and hippo (Hippotamus amphinius) and these two species do not always confine themselves to the park's boundaries. Hippos, and elephants in particular, are feared by the population residing near the park for the damage they cause through the consumption of cultivated crops in agricultural fields, and the for the threat they present to human life (KTL, 2010).

The park accommodates tourism with 2 permanent lodges and 3 campsites and supports research by visiting academics and community outreach with dedicated offices, housing, and lab space at Mulaushi Conservation Center near the entrance gate. In addition to the park and lodge management KTL employs about 90 local staff (KTL, 2010). 


\section{CBNRM and Park Outreach in Kafinda GMA}

In accordance with the terms of its MoU, KTL supports the neighboring community by donating to the Chitambo CRB (CCRB) $5 \%$ of its annual revenue from tourism. The CRB is also advised by a community relations director and community relations coordinator who work closely with its members and the 10 VAGs of Kafinda GMA in setting agendas and implementing agreed upon programs. Apart from its funding of the CRB, KTL also receives significant donor support from various international agencies and organizations which it uses to pursue its own community development programs. Occasionally the CRB receives direct funds from other organizations as well (KTL, 2010).

Achievements of KTL's community partnership over the past 10 years include the founding of a rural health clinic and a community center, renovation and construction of teacher housing, sponsorship of students, and workshops on agroforestry and alternative income generating activities to name a few (KTL, 2010). The history and quality of the CRB, in terms of its efficiency and effectiveness, are discussed in the results.

Despite the natural resource management remit of the CCRB there are few resources with revenue generating potential. In 2005 a hunting concession agreement was signed between the community and Busanga Trails Ltd. (BTL), a safari operator, and per terms of the contract BTL paid fees to CCRB which were to be used in the employment of additional scouts (ZAWA, 2005). It was anticipated that the hunting concession would bring significant benefits once commercial hunting began, however as of 2010 no hunting safaris have been 
conducted and the working relationship with BTL has all but terminated. If the hunting concession is renewed CCRB would receive a percentage of the concession fee and a percentage of hunting fees at a current negotiated rate of $15 \%$ and $45 \%$ respectively (ZAWA, 2006 ). 


\section{CHAPTER 2: METHODS}

\subsection{Selection of Study Site}

As the population surrounding KNP is under the authority of Chief Chitambo, and as Kafinda GMA is defined by the boundary of his chiefdom, the CRB's responsibility, as well as the community interventions of the park, are confined to, and treat equally of, all areas within the GMA and chiefdom boundary. The exclusivity of the GMA and bundled nature of affairs among its communities therefore logically suggested that all communities belonging to Kafinda GMA be included in the study area.

A target of $5 \%$ of households in the study area was set for the survey. However, suitably organized population data for the area did not exist. Population figures derived from the Office of Central Statistics were obtained for the year 2008, though they were not presented in accordance with boundaries observed in the study. As a result of the methods employed by the office in rural areas the numbers should be considered with caution. A preliminary rough estimate of approximately 35,000 people was assumed. Dividing the population by the average local household size of 6 gave almost 6,000 households. An initial conservative target for logistical purposes was thus set at 300 households for the entire study area. For statistical purposes more accurate and up-to-date household data was sought and obtained from each of 4 rural health clinics. Rural health clinics keep unofficial records on the population in their catchment areas and organize the data at a finer scale. A target number of households was 
then determined for each community derived from the data derived from the respective clinic.

\subsection{Survey Instrument}

A semi-structured questionnaire (see Appendix) was derived from Baral and Heinen (2007) and Shrivastava and Heinen (2007) and modified to suit the local realities as gathered from unpublished reports and as perceived by the author, a resident in the GMA from April 2008 to July 2010 as a volunteer in the US Peace Corps. Closed-ended questions pertained to respondent and household socioeconomic and demographic attributes, participation in conservation and development related efforts, and attitude towards conservation. Open ended questions pertained to the respondent's thoughts concerning the park and conservation in general. Conservation attitudes were scored from responses to 10 of 12 statements on a 3 point Likert scale, reflecting the most common form of this scale used in Africa (Anthony, 2007). The 12 attitude statements were designed to capture popular and relevant sentiments and beliefs regarding the state of natural resources, the necessity of laws protecting natural resources, the necessity of enforcing those laws, self-responsibility in conservation, and views towards the park. Responses to 2 of the 12 statements were omitted from analysis due to unreliability associated with misinterpretation of the statements' meaning.

Prior to implementation of the survey KNP staff were consulted for their input on the questionnaire and assistance in translating the attitude statements into Bemba. A Bemba instructor from a local government school also assisted in 
developing appropriately worded statements that retained the intended meaning. The statements were then back-translated into English to verify fidelity. Beginning in October 2009 the questionnaire was tested through several iterations on a total of 20 households and questions and statements were refined accordingly each time.

\subsection{Sampling Method}

A lack of an accurate or recent map of the study area showing human occupation (the most recent map available from the government being nearly 40 years old) dictated other means of household selection. A 2007 economic census of the area identified households by number, but few households remained with door tag identifiers, and of the few observed the identification numbers were washed out and no longer legible. An alternative random sampling method was therefore developed as a last resort. Catchment areas of clinics (or the relevant part of a catchment area if it included a region outside the study area) were treated as modules out of which random sampling could proceed. Population data from each clinic included the number of households by section - a traditional unit of administration recognized by the chief and containing 50-200 households - and the relevant part of each clinic's catchment area included between 3 and 17 sections. These data provided a relatively accurate method of sample size determination. If a catchment area was small then $5 \%$ of households in all sections were surveyed. If a catchment area was large, then for logistical considerations, a subset of sections was randomly 
selected and the percent of households surveyed in each section was adjusted upwards to reach the $5 \%$ target for the total catchment area.

Local escorts who were familiar with the undemarcated section boundaries were relied upon for navigation and for route planning. As most residents lived within sight of a common path, interval sampling was applied to select households for the survey. Depending on the length of paths and number of households in a section the interval was adjusted in order to avoid spatial sampling bias. However, most households in the chiefdom consist of multiple structures and are arranged in clusters or compounds which include households of extended family members. The housing pattern created difficulty in counting households so compounds were counted instead, on the assumption of 3 households per compound. Coordinates of sampled households were stored on a GPS and later superimposed on high resolution satellite imagery obtained from Google Maps to ensure spatial homogeneity of sampled households over occupied areas of each section sampled.

Potential respondents included all heads of household - by custom the male for married couples - or spouses of heads of household if the head was unavailable. If neither head nor spouse was available the nearest household with a potential respondent was found. It is custom for extended families representing 3 generations or more to live together in compounds, so for the purposes of this study, and by the criteria of the clinics, a household was considered a familial unit that is self-dependant for food. Much of the sampling period was during the planting or harvesting season, a time during which most 
household members are typically working in their fields before 10:00am. The survey was therefore conducted between the hours of 10:00am and 5:00pm. Though respondent selection by head of household is male biased, men were more likely than women to be absent from the household during the hours of sampling, somewhat correcting the bias. All households selected by interval sampling were surveyed, however those respondents who were employed currently or formerly by KTL or ZAWA, or were otherwise receiving direct benefits from KTL were excluded from analysis.

From November 2009 to May 2010268 households were sampled, 260 of which were included in the analysis. Though at least $5 \%$ of households were surveyed in the area sampled, because of time and logistical constraints the sampled area did not include all communities in the GMA. The two excluded communities of Gibson and Mukuku are estimated to comprise not more than 6,000 people and lie at the outer edges of the occupied area of the GMA. For the purposes of this study the community affiliation of a household was determined by the VAG that had responsibility in that area.

\section{Administration of questionnaire}

Escorts were also relied upon for the administration of the questionnaire. Nine different escorts were hired on the basis of their knowledge of the sections and facility with English. Escorts not only aided in translation, but as they were usually well known in the communities visited, their presence and assistance were significant factors in the earning of trust from respondents and the willingness of respondents to be open and truthful. Once a household had been 
selected and a respondent identified they were informed of the purpose of the survey, the anonymity of any information divulged, the lack of compensation for their time, and were finally given the option of participating. On only 3 occasions a potential respondent refused to cooperate. Questions on demographic and socioeconomic information were asked by the author in Bemba in order to further ease any potential anxiety on the part of the respondent, and occasional assistance was provided by the escort in interpreting responses. In order to ensure the accuracy of data, other household members were allowed to participate in the queries over factual information. To properly convey any subtlety of wording or emphasis in the communication of the attitude statements, these were read by the escort in Bemba. During the reading of the attitude statements attempts were made to isolate the respondent and all other household members were instructed to remain silent.

\subsection{Qualification and Manipulation of Data}

Despite efforts at quality control (explanation was prompted if responses to questions or statements appeared contradictory), it is likely some responses do not accurately reflect facts or attitudes of the respondents. Some error was expected in the reporting of field size for maize, as fields are not commonly measured in the absence of fertilizer. Exaggeration was anticipated in the reporting of months of food shortage, though estimates seemed to be honest. Exaggeration proved common however in the quantification of crop damage associated with elephants (when for example estimated areal extent of damage exceeded the cultivated area), so this information was not recorded. 
Respondents also sometimes seemed reluctant at first to consider themselves to be sellers of certain crops until the particular crops were suggested as possible answers. Some respondents, until corrected, were under the impression they were speaking on behalf of the local population in reporting what resources are harvested and sold. Less significantly, most respondents did not know their age off-hand and had to calculate it, frequently with some error.

Most problematic was the interpretation of responses to the attitude statements. Despite repeated instructions on how responses were to be made, respondents frequently reacted to statements with colloquialisms or truncations, only implying a certain response. Though escorts readily interpreted these reactions, error was potentially introduced with the ambiguity. Some statements also required a great degree of elaboration if the respondent did not understand the original wording, such that, while the sentiment was conserved, not all respondents responded to the same exact statement. Responses, especially to conservation related questions and attitude statements, were also likely influenced, to an unknown degree, by a desire on the part of the respondent to provide answers that accorded with what they presumed were the author's own values.

The issue of trust from respondents in the use of the data was an initial concern. Indeed, of the 3 respondents who refused to cooperate, 2 did so on suspicions of the author being affiliated with the park. However, as stated, the concern was mitigated by the association of respected community members with the project, and by the fact that many survey participants happened to know of 
the author and his ulterior purpose in the chiefdom with the United States Peace Corps.

\section{Data Manipulation}

Certain data were reclassified or used in the computation of additional variables. Analytically unwieldy data such as the highest level of education completed was re-coded into 6 possible values. Those with no formal educational experience, those with lower level primary experience (grades 1-4), those with upper level primary experience (grades 5-7), those with middle school experience (grades 8-9), those with secondary school experience (grades 1011), secondary school graduates, and post-secondary certificate earners were grouped separately.

The extreme poverty, lack of employment, and low scale of monetary transactions in the area result in low and highly inconsistent household incomes. The significance of household income is then reduced in proportion to food security, and savings (commonly in the form of livestock). Accurate accounting of annual income is rarely undertaken by households and so for the purposes of this study income was impractical to evaluate. Rather than a wealth index, a welfare index was developed to capture the state of a household in terms of its overall security in a subsistence environment. The components of the welfare index included months of food shortage subtracted from the number of crops sold, the presence of a vegetable garden, the sale of vegetables, the employment status of the respondent, employment status of a member of the 
household, alternative income sources, and a score based on the household's livestock.

A livestock score was calculated first by standardizing livestock species by units of chickens in relation to the local market sale value of a full size animal. Chickens were scored as 1 unit, ducks and guinea fowl 2 units, goats 5, pigs 15, and cattle 70 units. A total for all species was then summed. As the distribution was strongly and positively skewed, and as the standardized livestock values were out of proportion with the remainder of the welfare index, the values were scored by quantile. No points were assigned to the first quartile, 1 point to the second, 2 points to the third, 3 points to the fourth, and an additional point to the $10^{\text {th }}$ decile. In this manner the livestock value was brought into closer proportion with other factors of welfare than would have been achieved with a log transformation on livestock units.

Alternative income sources included income generating activities, remittances, pensions, piece work, and membership of an income earning club. As a proxy for wealth, or a potential component of the welfare index, the size of the respondents' maize fields were recorded. Maize does not grow well in the region without fertilizer so the size of the maize field roughly corresponds with the amount of fertilizer one can afford. However, this value was not recorded for the first 79 respondents so ultimately could not be included in the welfare index and was analyzed as a standalone variable.

To measure dependency on natural resources only resources sold by the household were recorded. The near uniformity of lifestyle and custom in the 
study area meant that all households were expected to regularly use or consume all of the resources listed (except where certain resources were not available) but not all households were expected to sell resources. This pattern of resource use conforms with documented patterns of use elsewhere in Zambia, where utilization only differs between wealthy and poor households by the frequency of the sale of resources (Bwalya 2004).

Data were entered in MS Access and statistical analyses were done using PASW Statistics 18. For tests of significance, an alpha value of .05 was used.

\section{Qualitative Data}

From April 2008 to July 2010 numerous formal and informal meetings and encounters were made with members of communities from throughout the GMA. Many meetings were in relation to the author's work as a Peace Corps volunteer to promote agro-forestry and alternative income generating activities, but topics discussed and information recorded touched on many aspects of life in the GMA and issues related to conservation. Meetings of the CRB and an area VAG were attended on several occasions, as was a meeting between representatives of the park and the local community at which many concerns and complaints about KTL's actions or anticipated actions were raised. One local and one national political campaign were also observed for tie-in to issues relating to the park.

Many discussions were held over the course of 2 years with KTL's community relations coordinator about past and current community interventions initiated by the CRB and KTL, and other relevant background information. 
Finally, in May of 2010, interviews with 3 key informants were held. The informants included a former chairman of the CRB, a chairman of an area VAG, and a former poacher and chairman of a reformed poacher group. Though conversations were held with the chief, interactions were infrequent and not pursued out of concerns over the reliability of resulting information. 


\section{CHAPTER 3: RESULTS}

\subsection{Demographic and Socioeconomic Characteristics of Respondents}

\section{Household Size and Population Demographics}

Of the 260 respondents $57.7 \%$ were male and $42.3 \%$ were female. The ages ranged from 16 to 86 with a mean age of $47.6 \pm 15.3$ years.

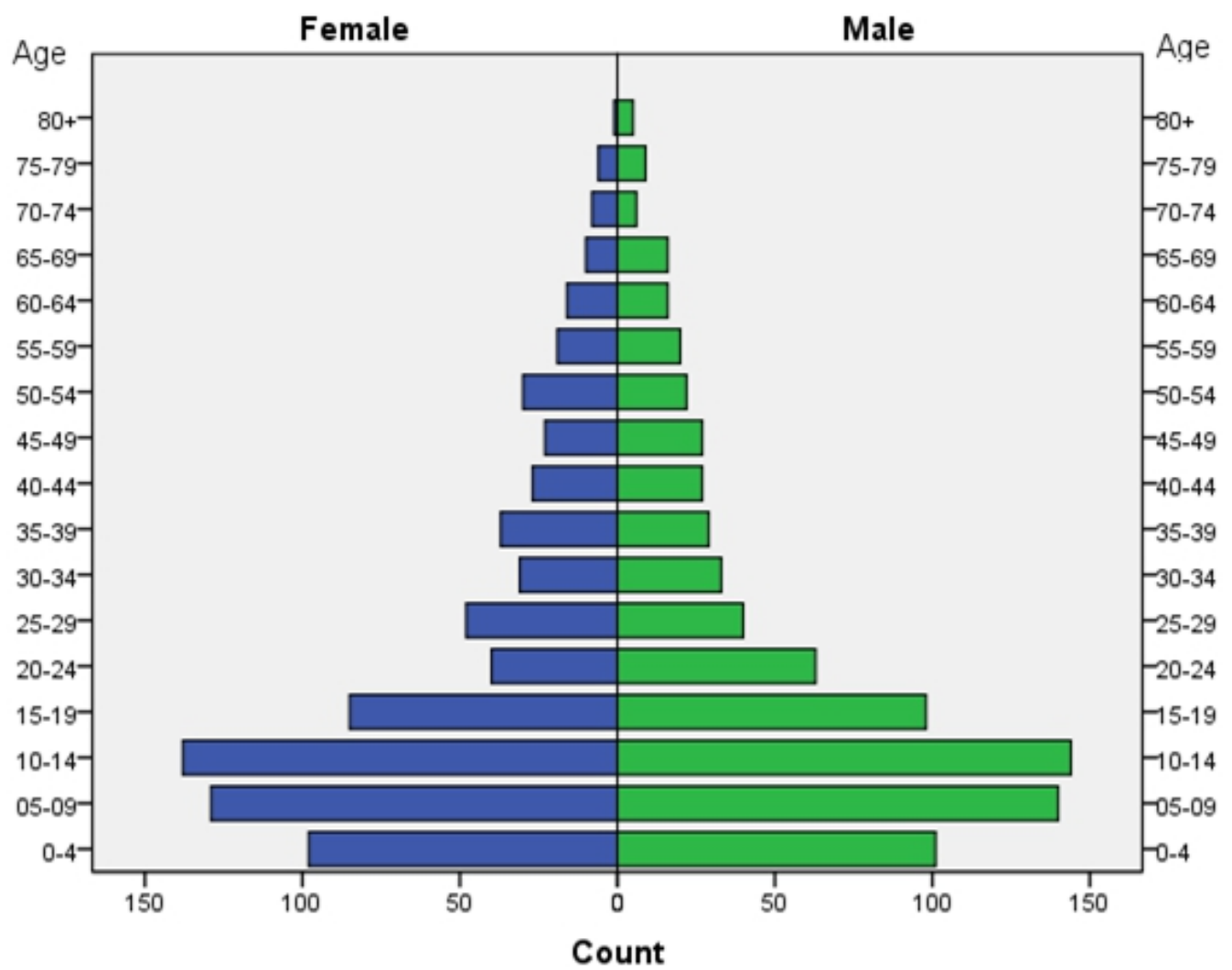

Figure 3.1: Population pyramid of sampled households

The mean household size was $6.0 \pm 3.3$ and households had between 1

and 23 members. A Kruskal-Wallis test indicated household size was not linked with the education level of the respondent $\left(x^{2}{ }_{6}=4.451, p=.616\right)$. The percentage of the population between the ages of 1 and 14, as derived from the ages of household members (Fig. 3.1), was $49.7 \%$, while the percentage of the population 75 and above was only $1.3 \%$. It is not known why the population 
pyramid narrows in the youngest two age classes, though it suggests

undercounting or possible sampling bias (related to the counting of compounds)

towards older couples who were less likely to have children in these two age classes.

\section{Distance to Park Boundary}

Respondents lived between 1.6 and $25.4 \mathrm{~km}$ from the boundary of the park with a mean distance of $10.6 \mathrm{~km}( \pm 6.5)$. Households were considered near the park if they were located within $5 \mathrm{~km}$ from the boundary. The majority (78.5\%) did not reside near the park.

\section{Education}

Only $2.8 \%$ of respondents received education at the secondary school level or higher and only $0.4 \%$ received a post-secondary level certificate (Table 3.1). The modal level at which education ceased was upper primary (39.5\%).

Table 3.1: Education categories and percent of respondents in each category

\begin{tabular}{|l|r|r|r|r|r|r|r|}
\hline Sex & $\begin{array}{c}\text { No } \\
\text { educatio } \\
\mathrm{n}\end{array}$ & $\begin{array}{c}\text { Lower } \\
\text { primar } \\
\mathrm{y}\end{array}$ & $\begin{array}{c}\text { Upper } \\
\text { primar } \\
\mathrm{y}\end{array}$ & Middle & $\begin{array}{c}\text { Lower } \\
\text { secondar } \\
\mathrm{y}\end{array}$ & $\begin{array}{c}\text { Secondary } \\
\text { grad }\end{array}$ & $\begin{array}{c}\text { Post } \\
\text { secondar } \\
\mathrm{y}\end{array}$ \\
\hline Male & $6.8 \%$ & $30.4 \%$ & $48.0 \%$ & $10.8 \%$ & $2.0 \%$ & $1.4 \%$ & $0.7 \%$ \\
\hline $\begin{array}{l}\text { Femal } \\
\mathrm{e}\end{array}$ & $32.7 \%$ & $35.5 \%$ & $28.2 \%$ & $2.7 \%$ & $0.9 \%$ & & \\
\hline Total & $17.8 \%$ & $32.6 \%$ & $39.5 \%$ & $7.4 \%$ & $1.6 \%$ & $0.8 \%$ & $0.4 \%$ \\
\hline
\end{tabular}

Post-primary matriculation rates were significantly higher for males $(14.9 \%)$ than females $\left(3.6 \% ; x^{2}{ }_{1}=8.779, d f=1, p=0.003\right)$. Females were also more likely than males to have no educational experience $\left(\mathrm{X}^{2}{ }_{1}=29.050, \mathrm{p}<\right.$ 
.001). Education level was significantly and negatively correlated with age ( $r=-$ $0.227, p<.000, n=258)$.

Low post-primary matriculation rates are not surprising given the distance between schools offering higher level education, the elevated cost of attendance, the failure rate on qualifying exams, and the opportunity cost to the families of enrolled students. Students may have to travel from home $20 \mathrm{~km}$ or more to attend middle school, pay additional fees for uniforms and other materials, and cannot support their family in the labors of the farm when they are gone. Primary school attendance alone suffers generally, and especially during the annual caterpillar harvest when students are retained at home in order to harvest caterpillars - a time that often coincides with the administration of qualifying exams. Secondary school enrollment is even more prohibitive as tuition is not subsidized by the government, and the distance to the nearest secondary school (over $100 \mathrm{~km}$ ) necessitates long absences from home.

The quality of education is constrained by high student-teacher ratios, the low amount of training received by many teachers, and the lack of materials. An illustration of the disparity between a government and community school is given in Table 3.2.

Table 3.2: Typical enrollment figures of local schools

\begin{tabular}{|l|r|r|}
\hline Name & $\begin{array}{l}\text { Chipundu basic } \\
\text { school (gov't) }\end{array}$ & $\begin{array}{l}\text { Musangashi } \\
\text { community School }\end{array}$ \\
\hline Grades & $1-7$ & $1-6$ \\
\hline Age range & $7-15$ & $5-15$ \\
\hline Enrollment & 300 & 213 \\
\hline Teachers & 8 & 2 \\
\hline students/teacher & 37.5 & 106.5 \\
\hline
\end{tabular}


Kasanka Trust, through its outreach office, supports environmental education in the GMA and education in general through visits by staff to local schools, hosting activity days for schools at the park, and by sponsoring approximately 20-25 students in secondary school each year. Additionally, environmental education may also be facilitated by materials provided by the Wildlife and Environmental Conservation Society of Zambia, though few schools had active subscriptions with the society.

Occupation:

Employment opportunities are severely limited in rural Zambia and subsistence farming is the primary livelihood. Because of the lack of capital, public sector jobs, such as in agricultural extension and education are more common than private sector jobs, though government jobs, with some exceptions, are usually filled by educated workers trans-located to rural areas from other parts of the country. Only two respondents of $260(0.8 \%)$ were employed outside of agriculture. Of these two respondents one was the headmaster of a primary school and the other was a proprietor of a local shop. Including the households of the former two respondents, $3.9 \%$ of households had a member who was employed. Of those employed, $70 \%$ had jobs connected to the park, employed either by ZAWA or KTL, and the most common of these jobs (40.0\%) was that of a wildlife scout. As there were 566 adults of working age (from 18 to the official retirement age of 55) among the households visited, the employment rate was $1.8 \%$ for the sampled population. Among the 276 men of 
working age the employment rate was $3.3 \%$, and of the 290 women, an employment rate of $0.3 \%$.

Migration

Respondents who migrated from a different chiefdom comprised $21.5 \%$ of the sample population. However, potentially included among the migrant group are individuals who were originally from the chiefdom but had emigrated prior to forming a household of their own and later returned to the chiefdom to settle. Most migrants came from within Central province (46.4\%), followed by the Copperbelt (32.1\%), Northern province (14.3\%), Lusaka province (3.6\%), and the Democratic Republic of Congo (1.79\%). Mean residency in the chiefdom among migrants $(n=56)$ was $16.6 \pm 10.0$ years. Migrants gave different reasons for immigrating to the chiefdom but most (67.9\%) did not fit a typology. Of the remaining reasons, retirement was most common $(25.0 \%)$, followed by marriage (17.9\%; by custom newly married men move to live with the family of the spouse), unemployment (16.1\%), and insufficient land (8.9\%). Only $12.5 \%$ of migrants had come from another GMA, and 6 of these 7 were from neighboring Bangweulu GMA. Because of ethnic and cultural homogeneity in the study area tribal affiliation was not recorded. All respondents spoke Bemba.

Internal migrants within Kafinda GMA comprised $8.1 \%$ of the respondents. On the reason for migrating, $14.3 \%$ responded that they were forced to move because of crop raiding by elephants. 


\section{Farm Production, Wealth, and Welfare}

Farming is virtually a universal livelihood in the study area. Only 3 respondents $(1.2 \%)$ did not have a field for farming but these respondents were all elderly women who were dependant on relatives for food despite living alone in a household of their own. Percentage of crop sales, for all crops sold, is given in Figure 3.2. In terms of economic value the three most important crops, by frequency sold, are groundnuts (58.0\%), maize (42.4\%), and cassava (29.2\%). However, as maize and cassava are staples, and as groundnuts are primarily a cash crop, the two most important crops grown throughout most of the chiefdom, in terms of food security, are maize and cassava. These crops are usually sold on condition of surplus but may sometimes be sold out of necessity for income.

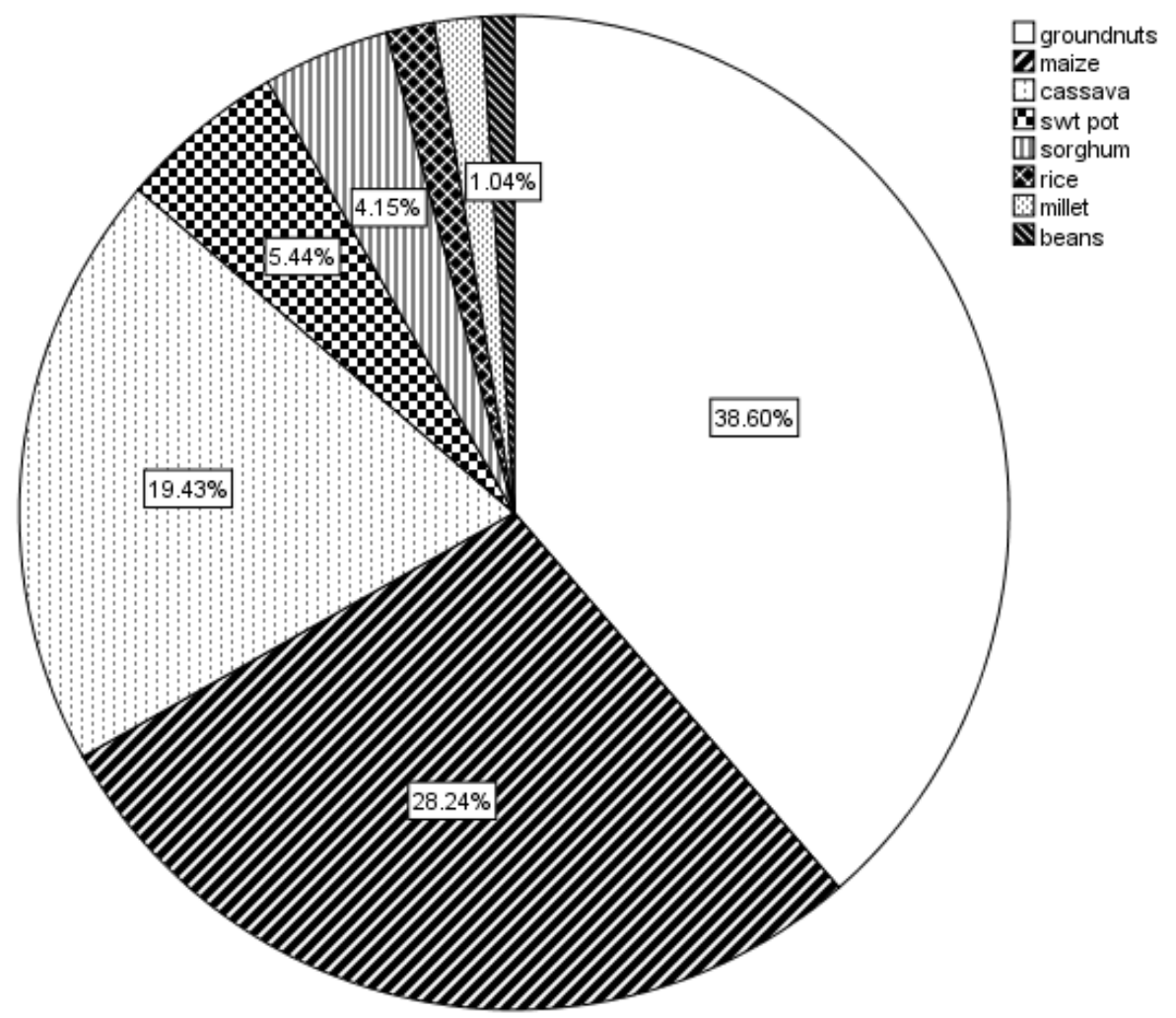

Figure 3.2: Percentage of crop sales for all crops sold 
Cultivation of vegetables from a garden is practiced by few $(15.0 \%)$ and constrained not only by inability to afford seeds but by a lack of seeds in the local market and the low quality of soils. As such, households with gardens tended to be found near streams where soil fertility was higher. Of those with gardens, $69.2 \%$ regularly sold their produce.

Total field size was difficult for respondents to accurately estimate and because of the dispersed pattern of settlement and availability of land it is anyways not a limiting factor for farm production. Instead, sizes of maize fields were recorded. As stated, the scale of maize cultivation is correlated with ability to purchase fertilizer and therefore a rough proxy of wealth. Mean size of fields for maize $(n=144)$ was 0.5 ha \pm 0.3 and ranged from 0.1 to 2 ha. A KruskalWallis test on maize field size indicates a significant difference across the 8 VAG areas $\left(X^{2}=32.998, p<.001\right)$, but because soil fertility was higher, and consequently food shortage lower in some of the relatively poor VAG areas, maize field size, despite its correlation with household welfare $(r=.333, p<.001$, $\mathrm{n}=144$ ), cannot be considered a reliable indicator of this variable. Though it may be considered an indicator of wealth, the small sample size precluded its inclusion in the welfare index for the regression model.

Almost half $(47.1 \%)$ of the respondents with fields $(n=257)$ experience regular food shortage. The duration of average annual shortage ranged from 1 to 9 months. Mean overall food shortage was 1.9 months \pm 2.3 , and the mean among those experiencing shortage was $4.1 \pm 1.6$ months. Though low yields associated with low soil fertility as well as lack of fertilizer may be assumed to 
explain most food shortage, $6.7 \%$ of respondents claimed food shortage because of flooding and $4.2 \%$ claimed food shortage as a result of crop raiding by elephants.

There was no difference in welfare between households near the park and other households $(z=-0.55, p=.581)$, nor was there a difference in per capita welfare $(z=-0.38, p=.703)$. There was also no difference in maize field size between near and far households $(z=-0.32, p=.749)$ and a chi-square test showed no link between food shortage and living near the park $\left(x^{2}{ }_{1}=0.78, p=\right.$ .447). Vulnerability and socioeconomic status of residents in the GMA appear then to be independent of proximity to the higher risk areas near the park.

Varied means, alternative to farming, of earning an income also exist. Income generating activities, defined as activities engaged in independently, were pursued by $13.8 \%$ of respondents. Chief among these activities (41.7\%) were the bartering of maize for fish in an adjacent chiefdom for subsequent sale locally, and beer brewing (25.0\%). Labor or piece work was engaged in by $6.9 \%$ of respondents, while $5.4 \%$ and $1.2 \%$ received remittances and pensions, respectively, and $3.1 \%$ belonged to an income earning club. There was no difference between the proportion of men and women earning an alternate income $\left(X^{2}{ }_{1}=0.412, p=.579\right)$, or engaged in an income generating activity $\left(X^{2}{ }_{1}=\right.$ $0.657, p=.417)$.

\section{Livestock}

A vast majority of respondents $(88.5 \%)$ kept one or more species of livestock. Commonly kept species were chickens, goats, and pigs. Rarer 
species included ducks or guinea fowl, and cattle. Percentage of households keeping each species and mean number of stock kept per household are given in Table 3.3. Though the data fit with expectations it obscures the fact that several large herds of cattle are kept in the chiefdom, owned by Tonga immigrants, and rented out for draught. The rarity and skewed distribution of cattle in this Bemba populated region then reflects the difference in culture between the Bemba and Tonga people.

Table 3.3: Percent of households keeping livestock species and number kept

\begin{tabular}{|l|r|r|}
\hline Species & \multicolumn{1}{|c|}{$\begin{array}{c}\text { \% of } \\
\text { Households }\end{array}$} & $\begin{array}{c}\text { Mean Per } \\
\text { Household }\end{array}$ \\
\hline Chickens & 83.1 & $4.9 \pm 4.1$ \\
\hline Goats & 36.2 & $1.4 \pm 2.7$ \\
\hline pigs & 20.4 & $0.7 \pm 1.7$ \\
\hline $\begin{array}{l}\text { ducks/guinea } \\
\text { fowl }\end{array}$ & 2.7 & $0.1 \pm 0.6$ \\
\hline cattle & 0.8 & $0.0 \pm 0.5$ \\
\hline
\end{tabular}

\section{Resources Sold}

Of 258 households $76.4 \%$ sold from one to 7 natural resources while the average household sold $1.9 \pm 1.7$ resources. Percentage of households selling each resource is given in Table 3.4. Some resources, namely caterpillars, fish, thatch, and chikanda (an orchid, the tuber of which is used in making a food) are sometimes sold to buyers who deliver the commodity to urban markets, though the volume and frequency of sale was not recorded. The sale of resources is factored by resource availability and access to markets, and in view of the relative availability of all basic resources (fuel-wood, thatch, etc.) it follows that 
the number of resources actually sold by a household is more an indicator of the degree of benefit derived from them rather than degree of reliance or dependence on natural resources. It has been reported elsewhere (Bwalya, 2004) that in forested communities in general relatively wealthy households and relatively poor households may not differ so much in their dependence on resources as they do in the way they utilize the resources, with wealthier households deriving commercial income from sale and poorer households deriving direct benefit from consumption of resources. Although the nature and pattern of resource exploitation was not the focus of this study, no correlation was found between the number of resources sold and household welfare $(z=$ $0.08, p=.187)$

Table 3.4: Percent of households selling resource types

\begin{tabular}{|l|r|}
\hline Resource & $\begin{array}{l}\text { \% of Households } \\
\text { Selling }\end{array}$ \\
\hline Caterpillars & 47.3 \\
\hline Fish & 45.8 \\
\hline Thatch & 36.2 \\
\hline Chikanda & 34.0 \\
\hline Mushrooms & 18.1 \\
\hline Charcoal & 16.6 \\
\hline Fruit & 14.6 \\
\hline Reeds & 9.3 \\
\hline Honey & 9.3 \\
\hline
\end{tabular}

Caterpillars are harvested annually from the onset of the rains in OctoberNovember and are an important relish at a time when food stores begin to 
dwindle. Efforts to maximize yield are often environmentally destructive though, and include the burning of the understory before the rainy season so as to allow a nutrient flush, enhancing the leaf growth of trees - the food of the caterpillar and felling trees in order to collect the caterpillars in the canopy. Chikanda is only found in dambos, or low-lying areas near streams, and is facing a growing national demand that threatens to diminish its abundance. The proportion of non-local consumption of the chikanda sold was not, however, ascertained.

Charcoal is primarily produced and consumed locally as a favored substitute for fuel-wood. Though urban populations are heavily dependent on the charcoal produced in Zambia's rural areas, Kafinda GMA was not observed to supply outside markets with significant amounts of this fuel.

\subsection{Conflict Issues in Park Outreach and Management}

\subsubsection{Crop Damage by Wildlife}

Elephants, and to a lesser degree hippos, garner among the local population significant and negative attention for the park and are largely responsible for negative sentiments directed towards park authorities. Elephants are said by some locals to come every week to eat their cassava roots, groundnuts, and maize. At times, herds of approximately 20 elephants were reported to the author to have raided villages. Local means of deterrence are limited and potentially dangerous. One method involves shooting bottle rockets in the direction of an elephant, and another method the lighting of fire near fields, accompanied by noise from shouting and drums. The latter method is more commonly practiced but may result in serious injury or death, as occurred in May 
2010 in the village of Mapepala where one farmer was killed defending his field. The tension between park authorities and locals is thus heightened by the issue of elephants, not only because of the anxiety from loss of food security or income, but from fear of the animals. The tension is also capitalized on by politicians. During one national campaign rally representatives of one party made promises to eliminate the elephants from the park and remove KTL's manager from his position. During another rally the national leader of the opposition party attempted to curry favor by empathizing with locals on the elephant issue and by highlighting the apparent discord between the biocentric values of the park managers and, what were portrayed as much more reasonable, the severely pragmatic values held by a local populace struggling to survive.

Attempts by KTL and ZAWA to allay concerns over elephants and mitigate damage were haphazard and infrequent. Communication of policies regarding crop damage compensation was also poor and inconsistent. At a meeting to inform an audience of over 100 community members on the intentions of KTL to proceed with a World Bank funded project in a nearby region, the agenda was sidetracked by the rare opportunity for those in attendance to voice directly to representatives of KTL and ZAWA complaints over the elephants and their suspicions over KTL's ambitions. Chronic fears were raised about expulsion of those settled close to the park and proposed wildlife corridors, though such plans for expulsions never existed. Those in attendance were also told by the ZAWA warden of a procedure to apply for compensation for crop damage. However I 
was later informed by the head ranger that ZAWA has no policy for compensation and no provision for compensation is made by the wildlife act. A representative of KTL later clarified that although no policy exists, KTL may be willing to compensate on their own on a case-by-case basis, though no compensation case was handled during the study period. Confusion on the issue of compensation may also be introduced by politicians. At a local meeting a member of parliament promised those gathered that in the future, victims of crop raiding by elephants would receive bags of maize.

A passive crop damage mitigation technique is being experimented with by KTL and is centered on the construction of "chili fences" utilizing capsicum oleoresin around crop fields to deter elephants and other wildlife. However such a technique is relatively expensive, requiring inputs such as engine grease to be provided by KTL. As a result of this contingency on funds the effort has been long stalled and was still in its infancy by the end of the study period.

Extent of crop damage due to wildlife could not be verified, though respondents reporting harassment from elephants and hippos were not more likely to experience food shortage $\left(x^{2}{ }_{1}=2.604, p=.129\right)$, nor did they experience longer durations of food shortage than those not reporting harassment from these two species. On the contrary, those reporting crop raids experienced on average a shorter duration of food shortage, though this result was not significant $(z=-1.88, p=0.060)$. In addition to elephants and hippos respondents suffered loss of crops from other species including monkeys (vervet monkeys and baboons), duiker, and bushpigs. Rodents and birds were reported to have 
caused damage by some respondents, however as these animals are pervasive pests they were not considered as wildlife for the purposes of this inquiry. From the 12 month period prior to the survey the majority $(72.7 \%)$ of households did not suffer any crop damage from wildlife. In the same time period though, elephants and hippos raided fields of $16.3 \%$ of households, while all other species combined caused damage in the fields of $14.6 \%$ of households (Table 3.5).

Incidence of elephant or hippo raids on crops is strongly linked with residence near the park $\left(x^{2}{ }_{1}=13.339, p=.001\right)$. However, the relationship between distance to the park and raids by elephants is not constant throughout the GMA, as illustrated in Figure 3.3. A number of factors, including the use of migration corridors, forage quality, and human population density combine to influence the frequency of travel by elephants to areas outside the park. As it appears that this relationship differs in the south and west of the park from the area to the north and east, these two areas are treated as separate regions in the analysis that follows. In the region to the north and east of the park $12.2 \%$ of households experienced crop raiding from elephants or hippos in the year prior to the study and a plot of incidence of attack from elephants or hippos for this population (constituting $85.4 \%$ of the total population in the study area) against the distance from the park indicated $90 \%$ of all crop raiding occurs within a distance of $11.4 \mathrm{~km}$. However, when the distance to a migration corridor that crosses through a relatively unpopulated region is factored in, the distance within which $90 \%$ of all raiding occurs is reduced to $4.7 \mathrm{~km}$. Of the sampled population 
in the east and north, $24.8 \%$ of households were found within a distance of 4.7 $\mathrm{km}$ to the park or elephant corridor, and of these households $41.8 \%$ experienced crop damage from elephants or hippos. Between a distance of 4.7 and $11.1 \mathrm{~km}$ only $2.2 \%$ of households were affected, and beyond a distance of $11.1 \mathrm{~km} \mathrm{no}$ households were affected.

In the region to the west and south of the park (constituting $14.6 \%$ of the total population of the study area), including the villages of Reuben and Mapepala, $39.5 \%$ of the sampled households suffered crop damage from elephants in the year prior to the study. The minimum distance from affected households to the park boundary was $7.3 \mathrm{~km}$, and mean distance $10.9 \mathrm{~km}$. The location of households, in terms of distance from the park, is therefore less a factor of the probability of attack, which is more than 3 times higher in this region.

Table 3.5: Percent of households experiencing crop damage from wildlife species in previous year

\begin{tabular}{|l|r|}
\hline Species & \% of Households Affected \\
\hline Elephants & 15.8 \\
\hline Monkeys & 7.3 \\
\hline Bushpigs & 6.5 \\
\hline Hippos & 1.5 \\
\hline Duiker & 0.8 \\
\hline
\end{tabular}




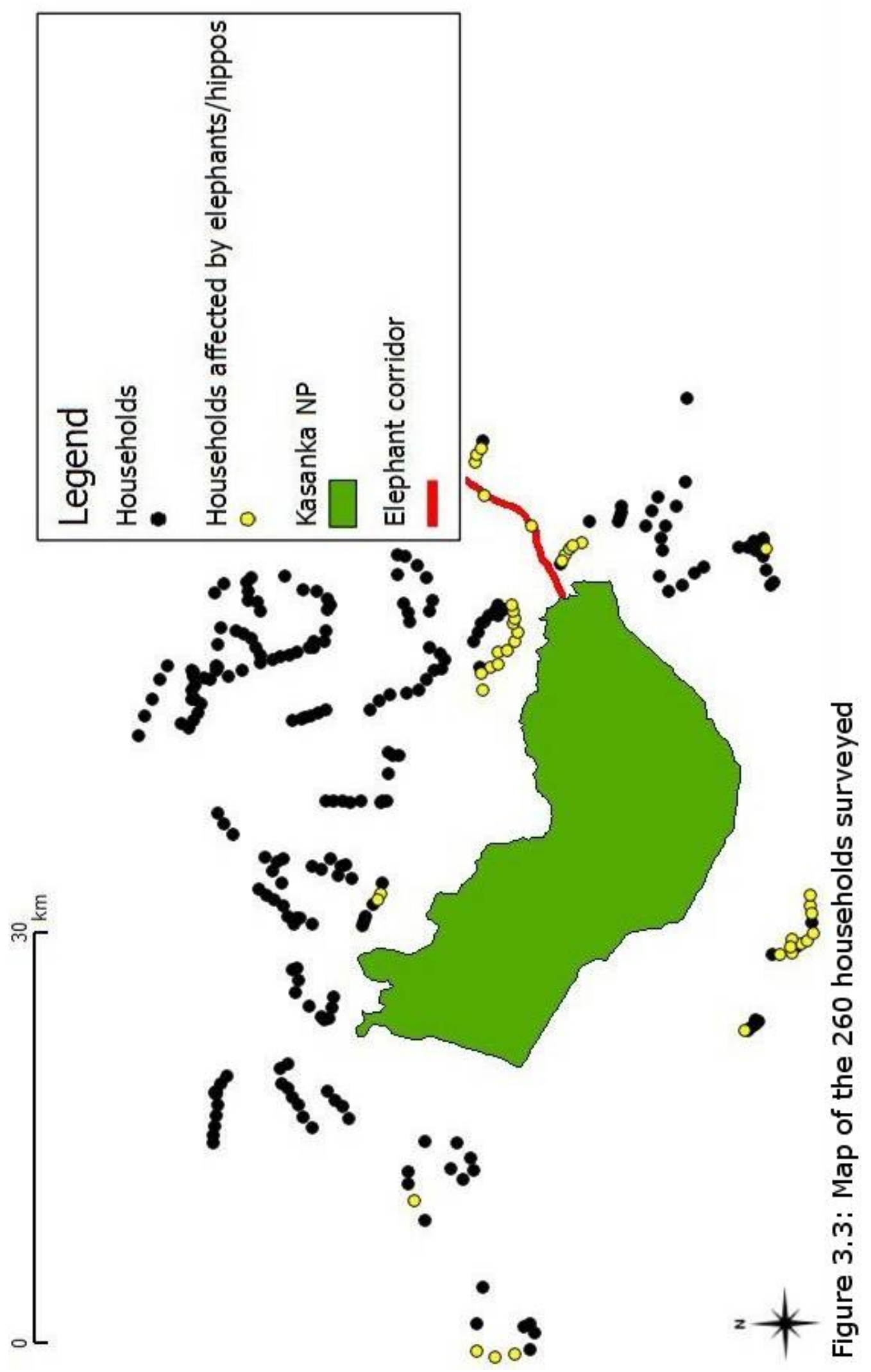

64 


\subsubsection{Poaching}

It is difficult to estimate the number of people who poach as a livelihood but though respondents were not queried on their connection with illegal activities, the rate of poaching was considered by many to be high. Park staff conservatively estimate that at least 10 animals are killed every day with the most common being puku and duiker. A former poacher and current chairman of a club for reformed poachers elaborated on the practice of poaching and the local market for bushmeat. Poaching is mostly a subsistence activity, and rarely are species targeted for anything other than meat. Park records confirmed that in the 10 years preceding the study only one elephant was illegally killed, and likely in defense of crops. The use of snares is the primary means of hunting, but locally made muzzle-loading rifles are also commonly used, especially in the rainy season when site selection for snare placement is confounded by overgrown game trails and the dispersal of game. Poachers originate mostly from within the GMA and most meat is sold locally. The presence of a checkpoint for part of the year along the road near the park, as well as other checkpoints throughout the country, deter transport of bushmeat to urban markets, though numerous routes exist for circumventing ZAWA inspection points and the proportion of bushmeat leaving the GMA could not be determined. Otherwise most sales are to the relatively wealthy, and the few residents with regular incomes such as government employees. A teacher at one village relatively far from the park conceded that bushmeat is offered to him for purchase almost every day. During the study period five attempted sales were 
witnessed, twice to government extension officers, twice to shopkeepers, and once to a club.

Information does not exist to allow characterization of the current trend in poaching with confidence, but historical context lends some perspective.

According to a former poacher, game populations were much higher prior to 1986, a time when even commercial poachers would operate. Enforcement was lax under ZAWA management, with scout presence low and patrols infrequent. Disregard of a conservation mandate was also reflected in certain practices common among the wildlife scouts. In lieu of rations, scouts were sometimes given 5 bullets with which to hunt puku and warthog (former ZAWA employee, pers. comm. 2009). Alarmingly, such a policy was endorsed by ZAWA as recently as the early nineties. Other game animals were occasionally shot to keep lions pre-occupied while tourists were on foot. However, enforcement in the park was stepped up after the arrival in 1985 of the founder of KTL, David Lloyd. Game populations inside the park were observed to be on the decline at that pivotal moment and the added risk of being caught reduced the incidence of poaching over the following years while sending other poaching activity out of the park and into the GMA.

The pattern of poaching effort and decline in game during the 1980's may be contrasted with the present situation. Although commonly targeted species of game have all but been eliminated from most of the GMA proper, counts of mammal populations from within the park suggest increasing numbers for some species, including sitatunga and warthog (KTL, 2010b), as well as puku (E. 
Farmer, pers. comm.). At the same time however it is believed by a former poacher, and representatives of the CRB alike, that poaching is on the rise. At approximately $\$ 5$ for $2 \mathrm{~kg}$, the price of bushmeat has increased in recent years. A former chairman of the CRB attributed the price increase in part to human population growth in the GMA and higher demand. While concurring with the apparent increasing trend in poaching, the chairman of the reformed poacher group attributed the price increase more to a higher risk of being caught. Data on enforcement effort were not obtained, though according to park staff the number of poaching related arrests declined by about half from 2000 to 2005 (when 43 arrests were made), though in recent years the number has increased slightly. Despite the origin of arrested individuals being routinely determined with their identification, this information is not officially recorded. Anecdotally however it is thought the largest proportion is from Mapepala, the part of the GMA closest to the nearest town of Serenje. The number successfully apprehended is of course a small fraction of those engaged in illegal hunting, and such is the brazen disregard of poachers for the law enforcement presence and response that it is not uncommon to hear from tourists or researchers of incidents of poaching by rifle occurring under their direct observation (such as from a tree hide) or within earshot.

\subsection{Participation in Conservation}

Respondents were asked if they or members of their family were currently or previously involved in the CRB or local VAG, employed by KTL or ZAWA, or 
had received any training, education, or assistance related to conservation efforts. Results appear in Table 3.6.

Table 3.6: Percent of respondents formally participating in conservation and outreach

\begin{tabular}{|l|r|r|}
\hline $\begin{array}{l}\text { Conservation Participation of } \\
\text { Family }\end{array}$ & $\begin{array}{l}\text { \% of Respondents' } \\
\text { Families }\end{array}$ & \multicolumn{2}{l|}{$\begin{array}{l}\text { \% of } \\
\text { Respondents }\end{array}$} \\
\hline In CRB/VAG & 11.5 & 3.5 \\
\hline In KTL/ZAWA & 13.8 & $0.0^{*}$ \\
\hline Received Training/Assistance & 9.2 & \multicolumn{1}{|r}{} \\
\cline { 1 - 2 } & &
\end{tabular}

* respondents known to be employed by KTL/ZAWA were not interviewed

A Mann-Whitney test indicates that respondents with families that have received training or assistance live closer to the park $(z=-2.69, p=.007)$, as do respondents with family members who have been employed by KTL or ZAWA ( $\mathrm{z}$ $=-2.26, p=.024)$. Respondents with family members in the CRB or VAG were neither better off in terms of absolute welfare $(z=-1.07, p=.284)$ nor per capita welfare $(z=-1.78, p=.859)$, and did not have larger maize fields $(z=-1.78, p=$ .076) than respondents without family members in the CRB or VAG.

Of respondents and families that have received training or assistance, the form of help varied from meetings of the CRB and other organizations at which they were taught the importance of conservation and how to manage natural resources $(50.0 \%)$, sponsorship of students at school $(25.0 \%)$, and provision by KTL of livestock or guidance on keeping livestock (12.5\%).

Since 1998, when KTL enlisted contact persons through which conservation sensitization was carried out in surrounding villages, development projects and conservation oriented community interventions have been ongoing. 
According to a former chairman of the CRB, contact persons were successful at improving communication between communities and KTL. The communication had previously been characterized by a lack of trust. It was not until 2002 though that the newly formed CRB received its first funding from KTL and other international donors. Early projects were designed on the principle of self-help. Clubs were invited to apply for grants for equipment (treddle pumps, manual presses, etc.) and livestock. However, with the exception of a few species of livestock the investments failed to make positive returns. In the judgment of the former chairman the clubs lacked cohesion, and interest could not be sustained because of the single and self-fulfilling purpose of many of the clubs - to qualify for such grants. Though the annual dividend received by the CRB is significantly augmented by development and charitable funds channeled through KTL (these additional funds have varied from $40 \%$ to more than $80 \%$ of the CRB's annual income), it was the assessment of both the former CRB chairman and a current VAG chairman that in most years the money is not sufficient to distribute amongst more than a small fraction of the VAGs or slated projects. In 2008 , for example, apart from paying the salaries of 6 wildlife scouts under the employment of the CRB and other administrative expenses, only a single project was implemented, the building and funding of a community school in the village of Kamaka (CCRB, 2009).

To the more endogenous difficulty of mobilizing the VAGs and the CRB, a difficulty compounding the monetary constraints, the informants offered different but non-mutually exclusive explanations. Attention was drawn to the lack of 
motivation of VAG members, who, for their role in such a grassroots organization, are relied upon to enhance the CRB's reach throughout the GMA. The inactivity of VAGs was attributed to a lack of compensation for meetings attended and work performed. However, and perhaps more significantly, the influence of the chief, as patron of the CRB, was thought to be a large source of disruption, since at least 2006, to an otherwise functioning institution. Conflicts of authority between the chief and KTL necessarily involved the CRB, as a partner with $\mathrm{KTL}$, and as a result the affairs of the CRB were stalled and interfered with. Conflict escalated during the study period, when in February, 2009, the chief dissolved the entire CRB. For an entire year the GMA was without community representation until elections to bring in a new board occurred in January, 2010. Notwithstanding the interruption, development and sensitization activities continued during this period, and, led by KTL, they included the funding and training of a new beekeeping cooperative.

A number of conservation oriented activities are practiced independently from KTL and the CRB. Clubs engaged in fish farming and agroforestry were found in several villages. The founder of one fish farming group stated he learned about fish farming from a meeting of the CRB and proceeded with developing the club's ponds despite receiving no response on requests for help to the CRB. Other clubs and individuals that had attempted fish farming ultimately abandoned the ponds because of limited success stemming from a lack of knowledge. Beekeeping was another activity in which a few clubs reported experience, though again, for lack of training none had success. 


\section{Awareness of and Comments on Local Conservation Institutions}

A random subset of respondents $(n=148)$ was asked to rate their satisfaction with the CRB or local VAG and elaborate on their regard of these institutions and conservation efforts in general. However, it became apparent during the course of the survey that a significant proportion of respondents either mistook the term "CRB" as a reference to the wildlife scouts (34.9\%) or otherwise did not have sufficient knowledge of the CRB to respond to the question (26.8\%). Only responses by those who knew the CRB's role $(38.3 \%, n=57)$ were recorded.

Respondents who expressed satisfaction with the CRB (66.7\%) offered different and sometimes multiple explanations for their approval. The most commonly cited reason (36.8\% of respondents) was for the work done in construction and support of schools and assistance of students. The CRB was credited with the general provision of developmental aid by a similar number of respondents $(31.6 \%)$, though only $5.3 \%$ specifically mentioned the use of the revenue dividend from KTL and none knew its value. Instruction and admonishment on the conservation and management of natural resources was appreciated by $15.8 \%$, and another $7.9 \%$ were appreciative of training in practical skills for household level development.

The explanations given by the $33.3 \%$ of respondents dissatisfied with the CRB also varied. Nearly half $(47.4 \%)$ complained that the CRB has failed to fulfill either specific responsibilities, or its more general responsibility of bringing development. About a fifth (21.1\%) of those who disapproved cited the selfish 
manner in which materials and funds are distributed amongst the members of the CRB and not shared with the community. Another fifth (21.1\%) were disappointed in the lack of VAG or CRB representation in their community and felt neglected because they had not been visited by the CRB.

A Kruskal-Wallis test of satisfaction rate indicated no significant difference across the villages of the 8 VAGs $\left(X^{2} 7=10.974, p=.140\right)$, however a chi-square test between the Reuben VAG area, having the highest rate of satisfaction $(91.7 \%, n=12)$, and all other VAG areas was significant $\left(x^{2}{ }_{1}=4.275, p=.045\right)$. A Kruskal-Wallis test of knowledge of the CRB indicated no significant difference across the 8 VAG areas $\left(x^{2}=11.083, p=.135\right)$, however a chi-square test between the Reuben VAG area, with the highest percentage of respondents knowing the CRB's role (66.7\%), and all other VAG areas was significant $\left(\mathrm{X}^{2}{ }_{1}=\right.$ $6.997, p=.018)$. The Reuben VAG area includes the village of Kamaka, the site of the last major CRB project prior to the CRB's dissolution. All 6 respondents in Kamaka who were satisfied with the CRB explained that the CRB built Kamaka community school. There was no significant difference in knowledge of the CRB between immigrants and non-immigrants $\left(x^{2}{ }_{1}=0.435, p=.549\right)$.

\subsection{Conservation Attitudes}

\subsubsection{Attitude Statements}

Responses to the 10 attitude statements were scored on a 3 point scale. Responses considered to represent a positive conservation attitude were awarded 1 point, responses reflecting a negative attitude were scored as -1 , and responses expressing a lack of an opinion were awarded no points. For 
purposes of statistical analysis on individual statements, only the percentage of positive responses was considered. Percentages of positive response to each statement are given in Figure 3.4.

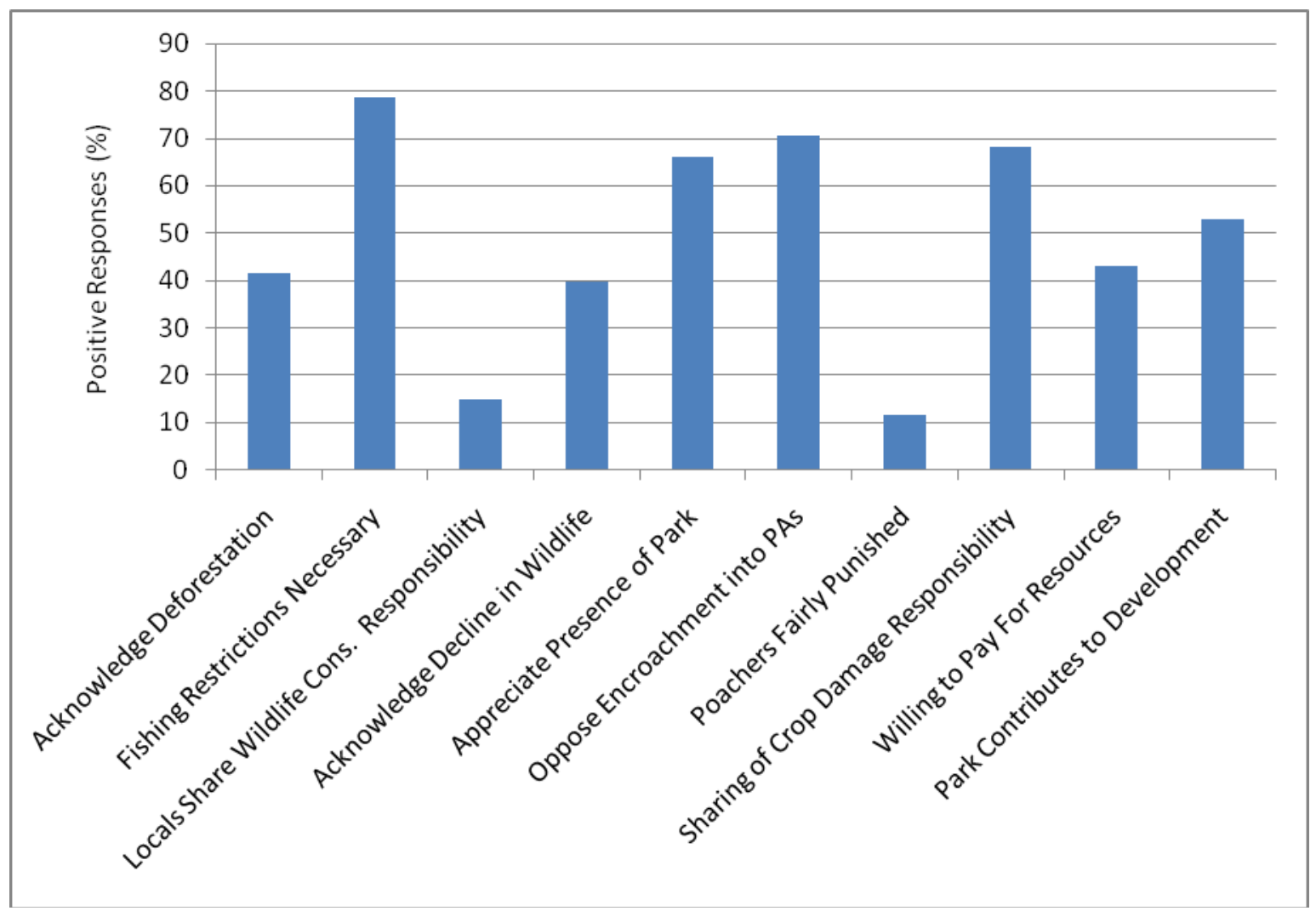

Figure 3.4: Percentage of positive response to each attitude statement

A significantly greater proportion of respondents $(66.7 \%)$ who had received conservation related training, or assistance from a conservation organization believed that forests had decreased near their homes in recent years $\left(X^{2}{ }_{1}=6.875, p=.015\right)$. Several respondents lamented that the chitemene system of slash and burn agriculture was the cause.

A significantly greater proportion of respondents (95.8\%) who had received conservation related training or assistance also believed that the annual 
4 month ban on fishing was necessary to prevent fish populations from declining $\left(\mathrm{X}^{2}{ }_{1}=4.575, \mathrm{p}=.034\right)$. Although there was no difference in response between those experiencing and those not experiencing food shortage $\left(x^{2}{ }_{1}=2.926, p=\right.$ .094), a Mann-Whitney test indicates there is a significant relationship with the months of food shortage experienced $(z=-2.042, p=.041)$. Respondents who experienced more food shortage were more likely to disagree about the necessity of the fish ban. There was no significant difference in responses between those who sold fish and those who did not $\left(x^{2}{ }_{1}=1.361, p=.287\right)$. Among villages, Chipundu scored significantly lower (56.4\%) in response to this statement than all other VAG areas $\left(x^{2}{ }_{1}=21.140, p<.001\right)$. One respondent in Chipundu commented that animals should be protected, but not fish because there are many.

A shared sense of responsibility among locals in conserving wildlife was not commonly expressed (14.9\%), and not even respondents with family members who are serving or who have served as wildlife scouts believed it was a responsibility incumbent on themselves $\left(X^{2}{ }_{1}=0.851, p=.440\right)$. One respondent defended this view, stating that, given the consequences, if he saw a friend with bushmeat it would be impossible for him to report the friend to the authorities. However, respondents with present or prior involvement in a VAG or CRB, or with family members involved in these institutions, were more likely (31.0\%) to disagree to it being a duty that should be left only to the scouts $\left(x^{2}{ }_{1}=6.788, p=\right.$ .022). Respondents were also more likely to express a shared sense of responsibility with education level $(z=-3.92, p<.001)$. 
Recognition of the general decline in wildlife over the past 50 years did not come in a significantly greater proportion (49.2\%) by respondents, aged 60 and over, who might have witnessed part of the decline $\left(x^{2}{ }_{1}=3.183, p=.101\right)$. The fact that populations of wildlife have recovered inside the park since the park's privatization may have led to a false perspective though, as some respondents explained that wildlife is more abundant now because it is being protected.

An almost significantly higher proportion $(75.4 \%)$ of respondents who knew the role of the CRB expressed an appreciation of the park $\left(\mathrm{X}^{2}{ }_{1}=4.342, \mathrm{p}=\right.$ $.051)$. Respondents with higher absolute welfare $(z=-2.898, p=.004)$ and less food shortage $(z=-2.878, p=.004)$ were also more likely to acknowledge benefits from the park. The statement phrased appreciation in terms of benefits experienced, however many respondents who answered positively referred to the existence value of wildlife found in the park and the desire that their children and grandchildren know the animals. Conversely, fewer respondents (45.2\%) who have suffered crop raiding from the problem animals most associated with the park (i.e., elephants and hippos) recognized benefits $\left(x^{2}{ }_{1}=9.787, p=.002\right)$. The negative relationship also held true for respondents who have suffered crop damage from the other, more dispersed species $\left(X^{2}{ }_{1}=4.659, p=.038\right)$. Some respondents who answered negatively mentioned crop raiding by elephants, and the prohibition on hunting among a starving population, but this statement also elicited reactions of indignation towards the wildlife scouts and accusations that the scouts are killing people. The latter sentiment was connected to an incident that occurred prior to the survey, in October, 2009, in which an off-duty wildlife 
scout beat a suspected poacher to death. The scout was later arrested on criminal charges related to the death. Across villages there was a difference in appreciation of the park with Mapepala scoring a significantly lower positive response rate $(36.8 \%)$ than all other villages $\left(x^{2}{ }_{2}=7.866, p=.010\right)$.

The anti-scout sentiment was also expressed in response to the statement on the punishment that poachers receive if they are caught. Most respondents $(88.5 \%)$ did not believe the punishment to be fair. It is generally known that poachers may face multiple year prison sentences, though no specific punishment was referred to in the statement. Some respondents again averred that poachers were being killed by scouts. Respondents who believed the punishment to be fair were more educated than those who did not believe the punishment to be fair $(z=-3.191, p=.001)$.

Absolute welfare was positively associated with the belief that people should not settle in PAs and that those who settle near PAs are partly responsible for any crop damage they endure from wild animals. It is not known how this association may be interpreted. There was no association between a refusal to attribute responsibility to those who settle near the park boundary with respondents who had suffered crop damage from elephants or hippos $\left(\mathrm{X}^{2}{ }_{1}=\right.$ 1.182, $p=.276)$. However, respondents closest to the park boundary and who had suffered crop damage may have had a different perspective on their distance and considered the statement as in reference to others. Across villages, respondents in Chipundu were less likely to object to the statement that people 
should not be allowed to settle within protected areas $\left(45.9 \%, X^{2}{ }_{1}=13.048, p=\right.$ $.001)$.

There was a significant and positive association between willingness to pay for natural resources harvested (including, but not limited to, fish, charcoal, chikanda, and caterpillars) and level of education $(z=-3.235, p=.001)$, absolute welfare $(z=-2.574, p=.010)$, and the number of resources the respondent's family sold $(z=-2.240, p=.025)$. Among individual resources, a significant relationship was only found with the sale of fish. A negative association was found to exist between willingness to pay and the months of food shortage experienced $(z=-2.725, p=.006)$ and age of the respondent $(z=-2.779, p=$ $.005)$.

There was a significant and positive association between absolute welfare and the belief that money from tourism in the park is helping with development in the area $(z=-2.957, p=.003)$. A greater proportion of respondents $(72.4 \%)$ who knew the role, and were satisfied with the work of the CRB also believed money from the park is helping with development, though this result was not significant $\left(X^{2}{ }_{1}=1.237, p=.186\right)$. A significant and negative relationship was found with this belief and months of food shortage experienced $(z=-3.727, p<.001)$. Several respondents elaborated that the money is helping students, but one respondent disagreed with the statement saying all the money goes to the chief. In Mapepala several respondents claimed the money helps other VAGs, but not in Mapepala, a view possibly related to claims of corruption against the former Mapepala VAG members. 


\subsubsection{Overall Conservation Attitude}

The attitude statement on the trend in wildlife numbers was excluded in a factor analysis, so 9 of the 10 statements were combined to produce an overall attitude score. Points were added from each statement and divided by the highest possible sum to calculate a score in percentage terms. The mean score of all respondents was $51.4 \%( \pm 16.1)$. If a respondent scored a $1(55.6 \%)$ or above they were considered to have a positive conservation attitude. For purposes of statistical analysis, respondents with neutral and negative attitudes were grouped together.

Table 3.7: Significance levels of predictors used in a linear regression model explaining conservation attitudes

\begin{tabular}{lcccc}
\hline Independent Variables & Coefficient & Std. Error & $\mathrm{T}$ & $\mathrm{p}$ \\
\hline Age & .006 & .012 & .502 & .616 \\
Gender (Female = 1) & .152 & .406 & .373 & .709 \\
Education Level & .837 & .196 & 4.267 & $.000^{*}$ \\
Household Size & .021 & .054 & .394 & .694 \\
Migration (From Diff'nt Chiefdom = 1) & -.194 & .433 & -.448 & .655 \\
Resources Sold & -.057 & .105 & -.537 & .592 \\
Crop Damage (Elephants/Hippos = 1) & -.213 & .480 & -.444 & .657 \\
Crop Damage (Other Species = 1) & -.275 & .547 & -.502 & .616 \\
Welfare Score (Per Capita) & .207 & .135 & 1.536 & .126 \\
Distance to Park Boundary & -.080 & .028 & -2.819 & $.005^{*}$ \\
Family Member in VAG/CRB (Yes = 1) & -.095 & .567 & -.168 & .867 \\
Family Member in ZAWA/KTL & 1.126 & .504 & 2.236 & $.026^{*}$ \\
(Yes = 1) & & & & \\
Received Training/Assistance & 1.253 & .627 & 1.999 & $.047^{*}$ \\
(Yes = 1) & & & & \\
\hline
\end{tabular}

$F_{13,238}=4.084, p<.001, R$-squared $=.182,{ }^{*}$ significant at $p=.05$ 
A linear regression model including 13 independent socioeconomic and demographic variables explained $18.2 \%$ of the variation in attitude scores (Table 3.7). Respondents had higher attitude scores the more educated they were ( $p<$ $.001)$, the closer they were to the park boundary $(p=.005)$, if a family member had been employed by ZAWA or KTL $(p=.026)$, and if they had received training or assistance from a conservation organization $(p=.047)$.

Though education was strongly associated with the attitude score in the regression model, the level of education of the respondent was not significantly correlated with attitude score when respondents who had completed grades 9 and above were excluded $(r=.109, p=.093, n=239)$.

Overall welfare was not a significant explanatory factor in the regression model, however the months of food shortage component of the welfare index was found to be linked with attitude scores. Respondents experiencing greater food shortage were more likely to have negative attitudes $(z=-2.785, p=.005)$. The score on livestock $(z=-.786, p=.432)$ and the size of the respondent's maize field $(z=-.979, p=.327)$ were not found to be associated with conservation attitudes.

Knowledge of the CRB was excluded as a variable from the regression because of a small sample size $(n=149)$. Respondents who knew the role of the CRB had a higher mean attitude score $(58.5 \pm 17.7 \%)$ than those who did not $(52.7 \pm 15.1)$, though this result was not signficiant $(z=-1.707, p=.088)$. 


\section{Conservation Attitude by VAG}

A plot of mean attitude score and percentage of respondents with positive attitudes by VAG area (Fig: 3.5) shows similar scores for all areas, with the exception of Chipundu. The Chipundu area was found to have a significantly lower mean attitude score than all other VAG areas $(t=4.399, p<.001)$ and a lower proportion of respondents with positive attitudes $\left(X^{2}{ }_{1}=17.742, p<.001\right)$. As respondents in Chipundu were on average much farther from the park boundary than all other respondents it is likely that the significance of the distance variable in the regression owes to the respondents' scores in this area. After excluding respondents from Chipundu, distance to the park boundary was not significantly correlated with attitude score $(r=-.023, p=.740, n=205)$, and the proportion of respondents with positive attitudes living near the park (within 5 $\mathrm{km}$ from the boundary) did not differ from that proportion of respondents not living near the park $\left(x^{2}{ }_{1}=0.002, p=1.000\right)$.

An analysis of VAG areas by variables used in the regression revealed that not all areas are equally represented through employment with KTL or ZAWA $\left(X^{2}{ }_{7}=24.004, p=.001\right)$, and not all areas have received the same amount of conservation related training or assistance $\left(X^{2} 7=19.509, p<.007\right)$. In Chipundu, significantly fewer family members of respondents had been employed by KTL or ZAWA than in all other VAG areas $\left(\mathrm{X}^{2}{ }_{1}=8.460, \mathrm{p}<.002\right)$. Though not significantly different $\left(3.6 \%, x^{2}{ }_{1}=2.606, p=.122\right)$, fewer respondents in Chipundu had received conservation related training or assistance than all but one other VAG area. In Miseshi, the area with the highest 
mean attitude score $(57.6 \% \pm 3.4)$, a significantly greater proportion of respondents had received conservation related training or assistance $\left(31.8 \%, X^{2} 1\right.$ $=14.634, p=.002)$. The Katonga VAG area, scoring second to last in both mean attitude score and percentage of respondents with positive attitudes, was only represented by 10 respondents but had greater incidence of food shortage $(90 \%$, $\left.X^{2}{ }_{1}=7.692, p=.007\right)$, and had a lower mean welfare score $(z=-3.418, p=.001)$ than all other VAG areas.

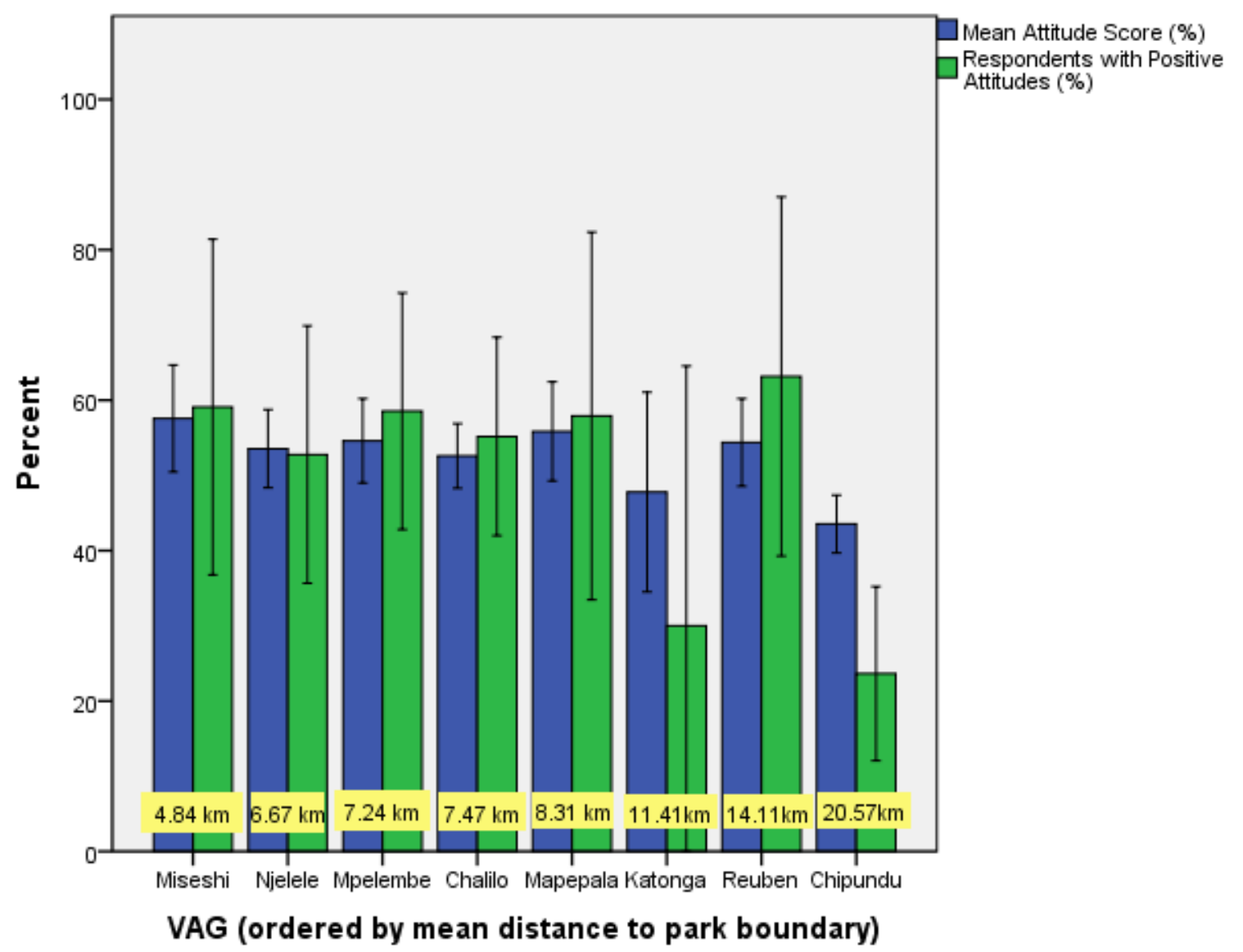

Error Bars: $95 \% \mathrm{Cl}$

Figure 3.5: Mean attitude score and \% of respondents with positive attitudes for all VAGs, ordered by distance to park boundary 


\section{CHAPTER 4: DISCUSSION AND RECOMMENDATIONS}

The results of the survey support the notion that conservation attitudes and support for conservation can be improved through participation by the community in outreach and management activities as well as through the sharing of benefits. On balance though, a number of mitigating and extenuating factors tend to reduce the effectiveness of park outreach efforts and undermine support for the park management authority.

\subsection{Impact of Outreach and Participation}

With respect to the loss of forest through the practice of chitemene it is noteworthy that less than half of the respondents (41.5\%) acknowledged that deforestation was occurring. Given the scattered distribution of households and relatively sparse settlement pattern in which household units are self-contained, and with farming fields typically "attached" to the living area (the opposite of the consolidated configuration of fields as in other regions of Zambia), it is perhaps an illusion permitted by narrow sighted perspectives that forest cover is not being lost. Afterall, a steadily increasing population, and even a preference for clearing secondary forest over fallow cover can currently be accommodated in parts of the GMA. In this context and in the absence of targeted education it is unreasonable to expect attitudes towards the clearance of forest to change until room for expansion is much reduced. That attitudes were observed to be positively linked with conservation education programs is a promising signal that at least awareness of deforestation as a problem can be spread at simple meetings, for example of the community resource board. Already the dangerous 
custom of burning the forest towards the end of the dry season when fires may spread out of control has been reduced, in part by the campaigning of KTL and CRB contact persons and the instrumental role of the chief in designating an earlier date for the commencement of burning. However, with respect to the issue of land conversion, the chief's decidedly anti-Malthusian declaration that too much land in the chiefdom has been left idle, and his remedial decree of a 10 child minimum for families in his chiefdom (Anonymous, 2009), casts serious doubt on his reliability as an ally in forest conservation. Though not an authoritative document, the dissemination of a recent land use plan for the GMA could also potentially be of use if it served to reinforce the notion of limited land availability. Positive conservation attitudes and knowledge of the ecological consequences of detrimental practices are not necessarily linked with behavior (Holmes, 2003) especially when behavioral alternatives are unavailable, but awareness of deforestation can be complemented by instruction in conservation farming and may help to improve the rate of adoption of this alternative method. Acknowledgement of the necessity of the seasonal fishing ban, though relatively high $(78.8 \%)$, does not accord with the observed widespread disregard of the ban. While the survey indicated a similar positive link with conservation education programs, attitudes towards fishing restrictions may reflect an understanding of the regretful outcome of collective noncompliance, rather than an individual willingness to observe the restrictions. The issue has also served historically as an outlet of tension between KTL and the CRB, and fishing dependent communities. Deliberate contravention of warnings by contact 
persons about the use of weirs, mosquito nets, and natural poisons would follow at the instruction of the Chief's advisors (chilolos) who were opposed to the imposition of authority by KTL in their villages (former CRB chairman, pers. comm., 2010). Here again, the link between conservation education and attitudes would be made more meaningful only when accompanied by provision of alternative livelihoods, including fish farming. The support of the chief in increasing the enforcement of restrictions should also improve compliance.

The significance of employment of family members in KTL or ZAWA as a factor explaining conservation attitudes agrees with evidence reported elsewhere (Anthony, 2007; Wainright \& Wehmeyer, 1998). However, employment opportunities will remain few near such a remote and relatively small park and just how acute or diffuse the experience of this relationship is within communities is not known. An economic multiplier effect of wage earners might benefit a whole village, but if a conscious connection between the park and the enhancement of economic services is not made then attitudes are not likely to change beyond those who are more directly benefitting.

\section{Impediments and Constraints on Outreach}

However large or small the observed influence of employment, education and outreach activities on attitudes is in reality, the potential impact is certainly much diminished by operational constraints, disruptions, and oversights of the CRB and KTL.

Despite success in fundraising (relative to the park's small size and visitation), the budget of the CRB in the best years is meager. The small 
operating budget may also explain the lack of evidence for elite capture by board members. A study comparing welfare between GMAs and non-GMAs in Zambia (Bandyopadhyay \& Tembo, 2010) found that the relatively wealthy were more likely to be elected to CRBs, and of board members, assets would mostly accrue to the relatively wealthy. Though some of the stated reasons for dissatisfaction with the CRB included accusations of selfishness towards its members, neither VAG nor CRB members had higher welfare scores than non-members. The possibility of an active hunting concession in the GMA is a tempting source of supplemental funds, however the recent failure of a safari operator to redeem its concession with commercial hunts, and the suspect basis on which the concession was originally awarded (lacking ecological justification) render this option unreliable (Manning, 2010). Faced with perennial budgetary limitations, there is a need for the CRB to generate its own revenue. A possibility exists, for example, in the taxation of timber that is commercially harvested, as currently royalties on this timber are only paid to the chief.

It is difficult, however, for the CRB to assert its authority and prove its relevancy when political space in the GMA is actively contested by the chief. The undermining of benefit distribution and democratic processes key to CBNRM is something that was experienced in the first evolutions of ADMADE in Zambia when dispensation of funds and employment opportunities were controlled by chiefs. The 1998 Wildlife Act redressed the issue by relegating chiefs to a ceremonial role as patrons. Yet while the management of CRBs has been structurally insulated against the potentially selfish ambition of traditional leaders, 
it has in this case been demonstrated that poor relations and a power struggle between a PA management authority secure in its legal remit and a strong willed chief can vitiate attempts to serve and empower a community. In January 2010 a new CRB was elected following the dissolution of the previous one by order of the chief, and following a period of over a year without representation of the community in the affairs of development and resource management. It remains to be seen though whether the new board has been afforded any greater stability. With the resignation of the former park manager in December 2009, it also remains to be seen whether his replacement, who arrived in early 2010 , will renew amicability and trust between KTL and the chief. The status quo in the state of relations between these key actors in the GMA is all the more regrettable considering the instrumental role, discussed above, that the chief can assume in setting and pursuing a conservation agenda with his advisors, headmen, and ultimately his subjects.

The low awareness and knowledge of the CRB and its relation to other conservation institutions was unexpected, but is not unusual among CBNRM programs (Anthony, 2007; Wainwright \& Wehrmeyer, 1998; Kaltenborn, Nyahongo, Kidegesho \& Haaland, 2008). Poor attitudes have been attributed to confusion or lack of knowledge about the roles of such institutions elsewhere (Anthony 2007), but no such statistical link could be established in this study. Mistrust and accusations of corruption have also followed from the impedance of the downward flow of information (Musumali et al., 2007). It is likely that even among those who understood the purpose of the CRB the perception of benefit 
from the organization was too low to sufficiently alter their outlook. More alarming was the frequency with which respondents conflated the CRB with wildlife scouts, who are commonly resented (discussed below). The perception of benefit from the park through the provision of developmental aid is of course critical to the continued support of conservation. It is thus a major failing of KTL's outreach program and of the CRB itself that ignorance prevails in the GMA. On the other hand it has been shown that when the operations of KTL and the CRB are not disrupted, and that when both work to fulfill the specific needs of a community, substantial approval, credit, and political capital can be earned. It was encouraging to find that in Kamaka, the remotest village of the GMA and site of a recently constructed community school, a level of awareness and satisfaction with the CRB that was missing elsewhere.

Part of the failure to spread awareness of the CBNRM process stems from the inactivity and neglect of some of the VAGs. It is hoped that with a new system of representation, whereby the chair of each VAG automatically earns membership on the CRB, a more equitable allocation of attention and resources will occur throughout the chiefdom. There is tentative evidence that at least in one community, encompassed by Chipundu VAG, relatively poor attitudes may be related to both a relative infrequency of CRB or VAG activity and the relative infrequency of employment by KTL or ZAWA among the villagers who reside there. 


\section{Socioeconomic Factors Relevant to Conservation Attitudes}

A regression analysis was useful in highlighting some of the variables responsible for shaping attitudes, but the coarse sensitivity of the closed question section of the survey, in which response values were averaged, may have overstated the significance of certain factors and understated others. A closer examination of the factors correlating with responses to individual statements reveals more nuanced relationships.

Mixed evidence exists in the literature for the significance of education in explaining positive attitudes in a CBNRM context. Some studies have reported links (Anthony, 2007) while others have not (de Boer \& Baquete, 1998). The education level of respondents was the strongest predictor of attitude scores in this study, however the level of education at which differences began to be seen $\left(9^{\text {th }}\right.$ grade $)$ is experienced by an inconsiderable proportion of the population. Availability and affordability of secondary education to residents of the chiefdom will not improve anytime soon, but a caveat to be made here regards the quality and nature of education currently available in the study area as compared with what existed at the time most respondents were in school. The survey reflects the influence of the schooling respondents were exposed to, on average, 3 decades ago, when environmental education took no precedence. The existence of school conservation clubs and the environmental education program of KTL have undoubtedly promoted awareness of conservation issues among schoolgoing children, though to what extent was not a focus of this study. 
Even less evidence exists in the literature for the relevance of wealth (Anthony, 2007; Gadd, 2005). This study was no exception. On the whole welfare did not significantly account for differences in attitudes. However, ambiguities in the measurement of wealth when formal accounting is rare make it difficult to differentiate between relatively poor and wealthy households. No obvious way to measure the wealth or welfare of a household suggested itself and consequently a conclusion with respect to wealth is unreliable. Less ambiguously, food security was shown to be a necessary condition before a conservation ethic prevails.

Interestingly, despite little to no direct benefits from the park accruing to residents of Kafinda GMA, respondents readily acknowledged an appreciation of the park's presence and the wildlife found there. This result is not uncommonly reported (de Boer \& Baquete, 1998; Gadd, 2005; Newmark \& Hugh, 2000) and reflects upon the discernments made by locals between PA management authorities on the one hand, and parks and nature on the other. It is perhaps an ability underappreciated by managers when it is assumed that lack of support for the management authority is due to a difference in underlying values. On the contrary, the results of this study suggest that a serious erosion of trust and perceived legitimacy of KTL and ZAWA among a segment of the local population is attributable to chronic and occasionally pronounced tension related to wildlife conflict and antagonism by wildlife scouts. 


\subsection{Factors Undermining Support for Conservation and Some Recommendations}

It is expected that relations between scouts and locals may at times come under stress given the duty of law enforcement officers to conduct arrests when laws are violated. Indeed, several physical altercations were observed between family members of recently arrested men accused of poaching and the scout responsible for their arrest. More troubling are the rare incidents when a suspected poacher is killed. The scout responsible for the beating death of suspected poacher during the study period may have been off duty and subsequently arrested for murder, but the harm done to the reputation of the scout force by such wanton abuses of power is not easily repaired. However, as this study indicates a positive influence of the presence of scouts and other employees of KTL and ZAWA on attitudes of extended family members, and potentially on the attitudes of the broader community, the employment of scouts should be valued as a strategy to foster support and understanding of management activities. As documented in Tanzania (Holmes, 2003) visitation by park staff, can also promote good relations.

Human-wildlife conflict plagues residents near PAs across Africa. As agents of the state, PA managers assume accountability, if not responsibility, in the eyes of those affected for the harm and destruction caused by wildlife - the property of the state (Osborn \& Hill, 2005). Tensions therefore rise when, by neglect or inability, managers fail to reduce or mitigate damage arising from this conflict. A small budget precludes KTL from effectively carrying the burden of 
accountability, and in ceding the issue by default has allowed elephants to become the focal point for anti-park sentiment. The negative sentiment is all too easily fanned by politicians and is shared among affected and unaffected members of the community alike. Though it is not possible to fully reconcile conservation interests with livelihood interests in the buffer zone of the park, this research indicates that a sense of futility and a lack of interest in effectively engaging with the community on this perennial problem has led to the politicization and exaggeration of grievance. Elephants are not the only species to consume crops, but strong perceptions of species associated with the state as problem animals are often independent of prior experience of crop raiding, and relate more to the perceived status of farmers with respect to the much more powerful park authorities and the state (Naughton-Treves \& Treves, 2005). Possible mechanisms for the mitigation of the conflict are discussed below.

The shorter duration of food shortage experienced by those reporting crop damage by elephants points to overriding considerations for the placement of farming fields as well as the intrinsic compensation of crop loss. The fertility of soil in the vicinity of the eastern boundary of the park, and in the wider area to the west of the park is known to be of relatively good quality. These areas also happen to be characterized by a high risk of crop raiding. The stress and suffering experienced from the constant threat of raids should by no means be minimized, especially when attacks by elephants are occasionally fatal, but average crop loss is probably well within collective coping capacity in affected villages given the higher crop yields. 
Compensation must nevertheless be provided to individual victims, to whom an advantage in higher average yields is no consolation. When compensation is made by neighbors the communal bonds of reciprocity are strengthened, but at the cost to KTL of support and accord with the community. Compensation of some sort by KTL on the other hand can serve to cultivate favorable regard. Formal compensation schemes, like the one erroneously promulgated by ZAWA at a village meeting, tend to lack feasibility, are fraught with technical difficulties in the verification and quantification of crop damage, and can lead to moral hazard if indemnified farmers become less vigilant as a consequence (Nyhus et al., 2005). The cost alone of compensation is likely prohibitive for a park with limited financial means. One alternative to straightforward compensation by KTL is an insurance scheme which farmers would pay into on an annual basis. However similar drawbacks exist with insurance schemes (namely, management costs, claim verification, and the avoidance of moral hazard). Adverse selection can also distort prices and reduce the overall value of such schemes if information does not exist to allow differentiation between areas of high and low risk. In the absence of information on risk a universal premium would apply and farmers facing low risk would be less willing to enter the scheme, doubtless compromising its viability. It is regardless unreasonable to expect farmers to support the cost of an insurance scheme alone.

A possible solution lies in the subsidization by KTL of an insurance scheme, or compensation with conditions placed on eligible members. Chili 
fence construction is already subsidized at almost full cost, yet the scale of human-elephant conflict and the lack of motivation for the adoption of this technique have already been discussed and place limits on its practicality. However, if this low tech method of deterrence is required for eligibility to receive insurance or compensation, moral hazard may be reduced along with the likelihood of crop raiding and the frequency of payment out of insurance or compensation funds, thereby reducing costs. Farmers would be encouraged to become more pro-active, taking pre-emptive crop defense measures as these would be seen as double investments - an investment against risk of crop loss and an investment in indemnity. In either case data on frequency and location of raids, such as that produced in this study, would be needed to determine area specific premium rates on insurance or discount rates on compensation. Data in the future could be collected from trained village monitors if these monitors were reinstated in the villages surrounding the park.

\subsection{Conclusion}

My research indicates that conservation attitudes and support of conservation in Kafinda GMA vary with certain socioeconomic factors intrinsic to households. More importantly, however, attitudes appear to be shaped by both stochastic and deterministic circumstances and narratives exogenous to households.

A small non-profit NGO managing a relatively remote, understocked, and low capacity national park will likely never generate revenue sufficient to provide benefits to the local population that outweigh the value of bushmeat and the 
costs of crop loss to wildlife. Nor will a CRB with few resources of its own to manage likely be empowered enough to return a sense of ownership over wildlife to the people it represents. These unfortunate realities will always necessitate a greater emphasis on law enforcement to maintain the GMA's populations of large mammals. The notion, however, that conservation attitudes can be improved through participation and benefit, it has been shown, remains valid and is ignored at the peril of losing support from the community, and the realization of diminished returns from management efforts.

Participatory approaches to development all too often devolve into selfvalidating processes through which local knowledge and planning are co-opted and used to legitimize the objectives of donor and implementing agencies (Mosse 2001). With an emphasis on rhetoric and the delivery of quantifiable results to attract program sustaining funds, evidence of ultimate outcomes is easily overlooked. The clinics and schools built, beekeeping and livestock rearing clubs started, chili fences constructed, and other project successes are all contravened by the low communication of project purpose, the lack of consistent engagement with the community to negotiate conflicts of various nature, and the poor relations with a traditional leader not reluctant to wield his veto power.

The value of and need for a dedicated information campaign to spread awareness of the status, goals, and accomplishments of KTL and the CRB should not go underappreciated. The enhanced downward flow of information and transparency should serve to strengthen institutional mechanisms of 
accountability, and with a modest but more effectively delivered message, and with innovation in strategies for conflict resolution this study suggests the potential for significant progress towards a more stable human and park landscape. 


\section{LIST OF REFERENCES}

Adams W., Hulme D. 2001. Changing narratives, policies and practices in African conservation. Pages 9-23 in D. Hulme, and M. Murphree, editors. African Wildlife and Livelihoods: The promise and performance of community conservation. James Currey, Oxford

[Anonymous]. 2009, May 3. Traditional leader urges couples to have at least 10 children. Lusaka Times. Retrieved April 15, 2011 from

http://www.lusakatimes.com/?p=11896\&cpage $=1$

Anthony B.. 2007. The dual nature of parks: Attitudes of neighboring communities towards Kruger national park, South Africa. Environmental Conservation. 34: 236-245

Balint P. 2006. Improving community-based conservation near protected areas: The importance of development variables. Environmental Management. 38:137148

Bandyopadhyay S., Tembo G. 2010. Household consumption and natural resource management around national parks in Zambia. Journal of Natural Resources Policy Research. 2:39-55

Baral N. Heinen J.. 2007. Resource use, conservation attitudes, management intervention and park-people relations in the Western Terai landscape of Nepal. Environmental Conservation. 34: 1-9

Barrow E., Gichohi H., Infield M. 2001. The evolution of community conservation policy \& practice in East Africa. Pages 59-73 in D. Hulme, and M. Murphree, editors. African Wildlife and Livelihoods: The promise and performance of community conservation. James Currey, Oxford

de Boer W. F., Baquete D. S. 1998. Natural resource use, crop damage and attitudes of rural people in the vicinity of the Maputo Elephant Reserve, Mozambique. Environmental Conservation. 25: 208-218

Bond I., Child B., Harpe D., Jones B., Barnes J., Anderson H. 2004. Private land contribution to conservation in South Africa. Pages 29-61 in B. Child, editor. Parks in Transition: Biodiversity, Rural Development, and the Bottom-line. Earthscan, UK.

Boonzaier E. 1996. Local responses to conservation in the Richtersveld National Park, South Africa. Biodiversity and Conservation. 5:307-314 
Bwalya S. M. 2004. Rural Livelihoods and Collective Action in Joint Forest Management in Zambia. Retrieved April 20, 2011 from http://www.saga.cornell.edu/images/cau-bwalya.pdf

Central Intelligence Agency (CIA). 2011. Zambia. In The World Fact Book. Retrieved February, 4, 2011, from https://www.cia.gov/library/publications/theworld-factbook/geos/za.html

Child B. 2004. Park agencies, performance and society in southern Africa. Pages 125-163 in B. Child, editor. Parks in Transition: Biodiversity, Rural Development and the Bottom-line. Earthscan, UK.

Child G., 2004. Growth of modern nature conservation in Southern Africa. In: Parks in Transition: Biodiversity, Rural Development and the Bottom-line. 6-27. Earthscan, UK.

Chitambo CRB (CCRB) 2009. Annual Financial Report. C/O KTL. Serenje.

Cumming D. 2004. Performance of parks in a century of change. Pages 125124 in B. Child, editor. Parks in Transition: Biodiversity, Rural Development, and the Bottom-line. Earthscan, UK.

Farmer L. 1992. Kasanka: A Visitor's Guide to Kasanka National Park. KTL. Serenje.

Gadd M. E.. 2005. Conservation outside of parks: attitudes of local people in Laikipia, Kenya. Environmental Conservation. 32:50-63

Grotpeter J. J., Siegal B.V., Pletcher J.R.. 1998. Historical Dictionary of Zambia (2nd ed.). Lanham, Maryland: Scarecrow Press, Inc.

Heinen J. 2010. The importance of a social science research agenda in the management of protected areas, with selected examples. Bot Rev. 76: 140-164

Holmes C. 2003. The influence of protected area outreach on conservation attitudes and resource use patterns: a case study from western Tanzania. Oryx. $37: 305-315$

Hulme D., Infield M. 2001. Community conservation, reciprocity, \& park-people relationships Lake Mburo National Park, Uganda. Pages 106-130 in D. Hulme, and M. Murphree, editors. African Wildlife and Livelihoods: The promise and performance of community conservation. James Currey, Oxford

Jones B., Murphree M. 2001. The evolution of policy on community conservation in Namibia and Zimbabwe. Pages 38-73 in D. Hulme, and M. Murphree, editors. African Wildlife and Livelihoods: The promise and performance of community conservation. James Currey, Oxford 
Jones B., Murphree M. 2004. Community-based natural resource management as a conservation mechanism: lessons and directions. Pages 63-103 in B. Child, editor. Parks in Transition: Biodiversity, Rural Development, and the Bottom-line. Earthscan, UK

Kaltenborn B., Nyahongo J., Kidegesho J., Haaland H. 2008. Serengeti National Park and its neighbors - do they interact? Journal for Nature Conservation. 16:96-108

KTL. 2010. About the Kasanka Trust. In Kasanka Trust. Retrieved October 21, 2010, from http://www.kasanak.com/frameset.htm

KTL. 2010b. Newsletter: second half of 2010. Retrieved February 20, 2010, from

http://www.kasanka.com/newspages/Kasanka\%20Trust\%20Quarter\%203and\%2 04\%202010\%20newsletter.pdf

Manning I.P.A.. 2010. Wildlife conservation in Zambia and the landsafe customary commons. Doctoral dissertation. University of Pretoria, Pretoria

Mosse D. 2001: People's knowledge, participation and patronage: operations and representations in rural development. Pages 16-35 in Cooke B., and Kothari U., editors. Participation: the new tyranny? ZED, London

Mudenda M. 2006. The challenges of customary land tenure in Zambia. Paper presented at Shaping the Change XXIII FIG Congress. Munich, Germany.

Murphree M.W. 2009. The strategic pillars of communal natural resource management: benefit, empowerment and conservation. Biodivers Conserv. 18:2551-2562

Musumali M., Larsen T., Kaltenborn B. 2007. An impasse in community based natural resource management implementation: the case of Zambia and Botswana. Oryx. 41:306-313

Naughton-Treves L. 1997. Farming the forest edge: vulnerable places and people around Kibale National Park, Uganda. The Geographical Review. 87:2747

Naughton-Treves L., Treves A.. 2005. Socio-ecological factors shaping local support for wildlife: crop-raiding by elephants and other wildlife in Africa. Pages 252-277 in Woodroffe R., Thirgood S., and Rabinowitz A., editors. People and Wildlife: Conflict or Coexistence? Cambridge University Press.

Newmark, W.D. and Hough, J.L. 2000. Conserving wildlife in Africa: integrated conservation and development projects and beyond. BioScience. 50:585-592. 
Nyhus P.J., Osofsky S.A., Ferraro P., Madden F., Fischer H. 2005. Bearing the costs of human-wildlife conflict: the challenges of compensation schemes. Pages 107-121 in Woodroffe R., Thirgood S., and Rabinowitz A., editors. People and Wildlife: Conflict or Coexistence? Cambridge University Press.

Osborn F.V., Hill C.M. 2005. Techniques to reduce crop loss: human and technical dimensions in Africa. Pages 72-85 in Woodroffe R., Thirgood S., and Rabinowitz A., editors. People and Wildlife: Conflict or Coexistence? Cambridge University Press.

Shrivastava R.J., Heinen J.. 2007. A microsite analysis of resource use around Kaziranga National Park, India: Impliciations for conservation and development planning. The Journal of Environment and Development. 16: 207

University of Zambia (UNZA). 2004. An assessment of potential integrated ecosystem management techniques in the miombo woodlands. Sustainable land management in the miombo woodlands ecosystem project. Ministry of Agriculture and Cooperatives.

U.S. Department of State (DOS). 2011. Background note: Zambia. In Zambia. Retrieved February, 4, 2011 from http://www.state.gov/r/pa/ei/bgn/2359.htm

Virtanen, P. 2003. Local management of global Values: Community-based wildlife management in Zimbabwe and Zambia. Society and Natural Resources. 16:179-190

Wainwright, C., Wehrmeyer, W. 1998. Success in integrating conservation and development? A study from Zambia. World Development. 26: 933-934

Wittemyer G., Elsen P., Bean W.T., Burton C.O., Brashares J.S.. 2008. Accelerated human population growth at protected area edges. Science. 321:123-126.

Zambia Wildlife Authority (ZAWA). 1998. Zambia Wildlife Act 1998. In Zambia Wildlife Authority. Retrieved October 20, 2010, from http://www.zawa.org.zm/Zambia_Wildlife_Act_1998.htm

Zambia Wildlife Authority (ZAWA) 2002. Memorandum of Understanding Relating to the Management of Kasanka National Park. ZAWA. Chilanga.

Zambia Wildlife Authority (ZAWA) 2005. Hunting Concession Agreement between the ZAWA and the Kafinda Local Community and Busanga Trails Ltd in the Under-stocked Hunting Blocks situated in the Kafinda Game Management Areas. ZAWA. Chilanga. 
Zambia Wildlife Authority (ZAWA). 2006. Community Based Natural Resources Management. In Zambia Wildlife Authority. Retrieved March 3, 2011, from http://www.zawa.org.zm/cbnrm.htm

ZAWA. 2007. Financial viability of current national parks and game management areas in Zambia: A case for the year 2006. Reclassification and effective management of the national protected areas system project. Zambia Wildlife Authority. 


\section{APPENDIX}

\section{Survey questionnaire}

Your participation in this survey is voluntary. You will not be paid for participating and you may refuse to answer some or all of the questions. Any information gathered in this survey will only be used for the purposes of research. The interview is completely confidential; your name will not be recorded. The purpose of this survey is to evaluate resource use patterns and conservation attitudes among people in this area of Central province. Your cooperation will help policy makers and planners make informed decisions.

No.

date

time of survey:

Ward: Section:

\section{Respondent's Data:}

Gender: $\quad$ Male Female Age:

Headman: household village snr village chilolo

Education (highest level completed):

\section{Information about Household Members:}

Please tell me the gender, age, education and occupation of your family members (the people living at this household).

\begin{tabular}{|c|c|c|c|c|}
\hline No. & Gender & Age & & \\
\hline \multicolumn{5}{|l|}{1} \\
\hline \multicolumn{5}{|l|}{2} \\
\hline \multicolumn{5}{|l|}{3} \\
\hline \multicolumn{5}{|l|}{4} \\
\hline \multicolumn{4}{|l|}{6} & \\
\hline \multicolumn{5}{|l|}{7} \\
\hline \multicolumn{5}{|l|}{$\begin{array}{l}8 \\
9\end{array}$} \\
\hline \multicolumn{5}{|l|}{9} \\
\hline \multirow[t]{2}{*}{ 5emale } & No. in & No. in & No. in & No. of \\
\hline & $\begin{array}{l}\text { Basic/Com. } \\
\text { school }\end{array}$ & $\begin{array}{l}\text { Middle } \\
\text { school }\end{array}$ & $\begin{array}{l}\text { Sec. } \\
\text { school }\end{array}$ & $\begin{array}{l}12 \\
\text { grads. }\end{array}$ \\
\hline Male & & & & \\
\hline
\end{tabular}


Are any household members employed? Yes No Occupations:

\section{Migration:}

Have you migrated to this village from elsewhere? Yes No

From where have you migrated to this village?

A non-GMA

Same chiefdom

When did you migrate here?

What was the reason to migrate here?

Insufficient land

Unemployment

Marriage

Retirement years ago.

A GMA

Different chiefdom

Farm Production:

Do you have fields for farming? Yes/size of maize field (limas) No

Do you grow enough food to support your family for the whole year?

Yes No

If no, how many months of food shortage do you experience from your own field? months.

Are you able to sell surplus production? Yes No If yes, what crops?

Are you maintaining a vegetable garden? Yes No If yes, for consumption or sale? 
What alternate sources of income do you depend on?

IGA(specify)

Money from relatives

Others (Specify)

\author{
Paid labour(specify) \\ Pension \\ Club
}

Have you suffered crop damage from wildlife in the past year? Yes No Species?

\section{Livestock Holdings:}

\begin{tabular}{l|l}
\hline Species & Number \\
\hline Cattle & \\
\hline Goat & \\
\hline Chickens & \\
\hline Pigs & \\
\hline Others (Specify) & \\
\hline
\end{tabular}

\section{Resource Uses:}

Of the resources that you harvest from the forest which do you sell and which are only for home consumption?

\begin{tabular}{l}
\hline Material Types \\
\hline Mushrooms \\
Charcoal \\
Thatch grass \\
Caterpillars \\
Fish \\
Fruit \\
Hardwood \\
Reeds \\
Cikanda \\
Honey \\
Others (Specify)
\end{tabular}


Conservation Attitudes:

\begin{tabular}{|c|c|c|c|}
\hline S. No. & Statements & A $\quad$ DN & $\mathrm{D}$ \\
\hline 1 & $\begin{array}{l}\text { Forests around your area have decreased in recent } \\
\text { years. }\end{array}$ & & \\
\hline 2 & & & \\
\hline 3 & $\begin{array}{l}\text { The number of fish will eventually decrease if the fish } \\
\text { ban is not better enforced. }\end{array}$ & & \\
\hline 4 & $\begin{array}{l}\text { Local people have no responsibility to conserve wildlife } \\
\text { because that is the job of the scouts }\end{array}$ & & \\
\hline 5 & There are more wild animals now than 50 years ago. & & \\
\hline 6 & $\begin{array}{l}\text { Overall, my living condition has benefited by the } \\
\text { presence of the park. }\end{array}$ & & \\
\hline 7 & $\begin{array}{l}\text { People should be allowed to live anywhere they want, } \\
\text { even if it is a place being reserved for animals and } \\
\text { plants. }\end{array}$ & & \\
\hline 8 & $\begin{array}{l}\text { The punishments given to poachers are excessively } \\
\text { harsh. }\end{array}$ & & \\
\hline 9 & $\begin{array}{l}\text { Those people who settle close to the boundaries of } \\
\text { protected areas are partly responsible for crop damage } \\
\text { that is caused by wildlife. }\end{array}$ & & \\
\hline 10 & $\begin{array}{l}\text { Natural resources in this area will decline and when } \\
\text { your grandchildren grow old they will not find them the } \\
\text { same. }\end{array}$ & & \\
\hline 11 & $\begin{array}{l}\text { Are you willing to pay a small fee for some of the } \\
\text { natural resources you harvest if it would help to } \\
\text { conserve the resources? (for example: fish, caterpillars, } \\
\text { icikanda). }\end{array}$ & & \\
\hline 12 & $\begin{array}{l}\text { The money from tourism in the park is helping with } \\
\text { development in this area. }\end{array}$ & & \\
\hline
\end{tabular}

\section{Participation and Benefits:}

Are you or any of your family members elected in the VAG/CRB?

Yes relation:

No

Have you or any of your family members been employed in Kasanka? 
Yes relation:

No

Have you or your family members ever received any kind of training or assistance from the VAG/CRB, KTL?

Yes No What type of assistance?

Miscellaneous:

Are you satisfied with the work of VAGs and the CRB? Yes No

Why?

Knew the role of the VAGs/CRB Yes No

Comments:

Interview conducted in: Bemba English 